\title{
Mesenchymal stem cell-based treatments for COVID-19: status and future perspectives for clinical applications
}

\author{
Lijun Chen ${ }^{1}$ · Jingjing $Q u^{2} \cdot$ Farhin Shaheed Kalyani ${ }^{2} \cdot Q^{i}$ Zhang $^{1} \cdot$ Lingzhi Fan $^{3} \cdot$ Yangxin Fang $^{1} \cdot$ Yifei $i^{1}$. \\ Charlie Xiang ${ }^{1}$ (1)
}

Received: 20 July 2021 / Revised: 17 November 2021 / Accepted: 13 December 2021 / Published online: 20 February 2022

(C) The Author(s), under exclusive licence to Springer Nature Switzerland AG 2022

\begin{abstract}
As a result of cross-species transmission in December 2019, the coronavirus disease 2019 (COVID-19) became a serious endangerment to human health and the causal agent of a global pandemic. Although the number of infected people has decreased due to effective management, novel methods to treat critical COVID-19 patients are still urgently required. This review describes the origins, pathogenesis, and clinical features of COVID-19 and the potential uses of mesenchymal stem cells (MSCs) in therapeutic treatments for severe acute respiratory syndrome coronavirus 2 (SARS-CoV-2)-infected patients. MSCs have previously been shown to have positive effects in the treatment of lung diseases, such as acute lung injury, idiopathic pulmonary fibrosis, acute respiratory distress syndrome, lung cancer, asthma, and chronic obstructive pulmonary disease. MSC mechanisms of action involve differentiation potentials, immune regulation, secretion of anti-inflammatory factors, migration and homing, anti-apoptotic properties, antiviral effects, and extracellular vesicles. Currently, 74 clinical trials are investigating the use of MSCs (predominately from the umbilical cord, bone marrow, and adipose tissue) to treat COVID-19. Although most of these trials are still in their early stages, the preliminary data are promising. However, longterm safety evaluations are still lacking, and large-scale and controlled trials are required for more conclusive judgments regarding MSC-based therapies. The main challenges and prospective directions for the use of MSCs in clinical applications are discussed herein. In summary, while the clinical use of MSCs to treat COVID-19 is still in the preliminary stages of investigation, promising results indicate that they could potentially be utilized in future treatments.
\end{abstract}

Keywords Coronavirus disease 2019 (COVID-19) - Severe acute respiratory syndrome coronavirus 2 (SARS-CoV-2) . Mesenchymal stem cell · Cellular therapy

\section{Introduction}

Charlie Xiang

cxiang@zju.edu.cn

1 State Key Laboratory for Diagnosis and Treatment of Infectious Diseases, National Clinical Research Center for Infectious Diseases, Collaborative Innovation Center for Diagnosis and Treatment of Infectious Diseases, The First Affiliated Hospital, College of Medicine, Zhejiang University, Hangzhou 310003, Zhejiang, People's Republic of China

2 Department of Respiratory Disease, Thoracic Disease Centre, The First Affiliated Hospital, College of Medicine, Zhejiang University, Hangzhou 310003, Zhejiang, People's Republic of China

3 Central Laboratory, The First Affiliated Hospital, College of Medicine, Zhejiang University, Hangzhou 310003, Zhejiang, People's Republic of China
In December 2019, there was a global outbreak of severe acute respiratory syndrome coronavirus 2 (SARS-CoV-2), known as the coronavirus disease 2019 (COVID-19) [1, 2]. Cross-species transmissions lead to the outbreak, which was found to seriously endanger human health $[3,4]$. The main routes of transmission were identified as respiratory droplets, direct contact, fecal-oral, mother-to-child, and aerosols $[5,6]$. On March 11, 2020, the WHO issued an early warning of the global spread of COVID-19 and increased the impact level from epidemic to "global pandemic" [7]. As of November 17, 2021, over 253, 640, 000 cases of COVID19 infection and 5, 104, 899 subsequent deaths were confirmed worldwide (https://www.who.int/emergencies/disea ses/novel-coronavirus-2019). Due to the suddenness of the outbreak, there were no effective antiviral drugs available 
to immediately eliminate COVID-19. Furthermore, to date, effective control using drugs has not yet been achieved and is thus still in development. Although the spread rate of SARSCoV-2 infections was initially controlled, new cases and mortality rates are still increasing globally. Of the reported COVID-19 cases globally, $13.8 \%$ were classified as severe, $6.1 \%$ were critical, and $2.3 \%$ were fatal $[8,9]$. Therefore, the development of effective treatments for COVID-19 remains imperative.

Of the great efforts made worldwide to control COVID$19[10,11]$, vaccine research has clearly been important in controlling infection rates [12-17]. Initially, Zhu et al. [18] and Folegati et al. [19] reported that in human clinical trials the COVID-19 vaccine had acceptable safety, tolerance, immunogenicity, and efficacy. Many other organizations then quickly developed effective vaccines, such as the BNT162 mRNA vaccine sponsored by Pfizer Inc. and BioNTech SE [20-22], the adenovirus ChAdOx1 nCoV-19 (AZD1222) vaccine sponsored by AstraZeneca in the United Kingdom [23, 24], the mRNA-1273 vaccine co-sponsored by Moderna, Inc. and the National Institute of Allergy and Infectious Diseases of the United States of America [25, 26], the recombinant NVX-CoV2373 vaccine developed by Novavax, Inc. in the United States of America [27, 28], the recombinant Sputnik V vaccine co-sponsored by Gamaleya Research Institute of Epidemiology and Microbiology and the Health Ministry of the Russian Federation of Russia [29], the recombinant adenovirus type-5 (Ad5) vectored vaccine co-developed by the CanSino Biologics Inc. and Beijing Institute of Biotechnology of China [18, 30], the inactivated vaccine (BBIBP-CorV) sponsored by the Beijing Institute of Biological Products Company Limited of China [31, 32], the inactivated vaccine (CoronaVac) sponsored by Beijing Sinovac Life Sciences of China [33, 34], and the inactivated vaccine (BBV152) sponsored by Bharat Biotech International Limited, the Indian Council of Medical Research, and the National Institute of Virology of India [35, 36]. Clinical research results found that these vaccines were safe and effective [21, 22, 26, 28-30,36], and some were mass produced for practical application. To date, billions of people have now been vaccinated for COVID-19, and the data continue to show that they are safe without serious negative side effects [37, 38]. All approved COVID-19 vaccines will continue to be monitored for long-term safety. Furthermore, some drugs (such as remdesivir, favipiravir, and dexamethasone) have also shown positive preliminary results in randomized, controlled, open-label clinical trials [39-41]. However, there are currently no specific drugs for the treatment of COVID-19, and consequently, novel methods to treat SARS-CoV-2 are urgently required.

Mesenchymal stem cells (MSCs) have the capacity to self-renew and differentiate, and MSC-based therapies have received much attention in both basic medicine and clinical research [42-45]. MSCs can be acquired from most human tissues, including but not limited to, bone marrow (BM), adipose tissue (AD), umbilical cord (UC), Wharton's jelly (WJ), peripheral blood, menstrual blood, placenta, endometrium, amniotic membrane, amniotic fluid, fetal, dental pulp, urine, liver, lung, spleen, intestine, muscle, and synovium [46-50]. MSC-based therapies mainly rely on their self-renewal ability, pluripotent differentiation, low immunogenicity, anti-inflammatory function, and a homing ability to damaged tissues [51-55]. Importantly, MSCs have a unique immuno-regulation mechanism for mediating innate and adaptive immune responses $[56,57]$. An increasing number of clinical studies have shown great promise in various diseases through the transplantation of MSCs [42, 58-60]. Wilson et al. used allogeneic MSCs in patients with acute respiratory distress syndrome (ARDS) and found no adverse reactions, such as hypoxemia, arrhythmia, and ventricular tachycardia, and also showed good therapeutic effects [61]. Our group reported that menstrual blood-derived MSC implantation significantly reduced the mortality of ARDS patients induced by the influenza A (H7N9) pandemic [62] Angiotensin-converting enzyme 2 (ACE2) has been verified as a receptor by which SARS-CoV-2 enters target cells [63, 64]. Interestingly, researchers have shown that MSCs do not express ACE2 and are resistant to SARS-CoV-2 infection $[65,66]$. Therefore, MSC-based treatments may be promising for patients with COVID-19, especially those in which the disease is classified as severe or critical.

This review focuses on the potential mechanisms of MSCs and clinical studies using MSC transplantation for the treatment of COVID-19. The aim is to improve understanding of the current MSC-based treatments for COVID19 and provide guidance for their further applications in clinical medicine.

\section{Epidemiology of COVID-19}

\section{Origins of SARS-CoV-2}

Since the beginning of the twenty-first century, three coronaviruses have crossed the species barrier and been transmitted from animals to humans. These viruses include severe acute respiratory syndrome coronavirus (SARS-CoV), Middle East respiratory syndrome coronavirus (MERS-CoV), and SARS-CoV-2 [67, 68], all of which can cause fatal lung damage. Human-to-human transmission of SARS-CoV, MERS-CoV, and SARSCoV-2 mainly occurs through respiratory droplets when an infected person coughs/sneezes/talks [69]. The newly discovered coronavirus, SARS-CoV-2, is an encapsulated, positive sense, single-stranded RNA virus that causes global fulminant infections $[70,71]$. SARS-CoV-2 is in 
the Sarbecovirus subgenus of the $\beta$-coronavirus genus. According to genome comparisons, the similarity between SARS-CoV and SARS-CoV-2 at the nucleotide level is approximately 79\% [72]. SARS-CoV and MERS-CoV viruses are thought to originate from bats, while civet cats and dromedaries are intermediate hosts of SARS-CoV and MERS-CoV, respectively, which cause zoonotic transmission $[73,74]$. Preliminary epidemiological investigations have shown that the source infection for SARS-CoV-2 can be traced back to a live seafood wild animal market [75]. Genome sequence analysis showed that SARS-CoV-2 was very similar to a bat coronavirus (approximately $96 \%$ identical), and it is considered that SARS-CoV-2 may have been transmitted to humans through bats [72, 76, 77].
Interestingly, Lam et al. found several speculative pangolin coronavirus sequences that were $85.5-92.4 \%$ similar to SARS-CoV-2 [78]. Additional studies have shown that there are a variety of Malayan pangolin (Manis javanica) coronavirus lineages similar to SARS-CoV-2 genes, further supporting the hypothesis that pangolins are potential intermediate hosts $[78,79]$. Recently, researchers discovered that minks, cats, and dogs are also sensitive to SARSCoV-2 [80-82], but whether they are intermediate hosts requires further investigation. While bats and pangolins are currently considered to be the intermediate hosts of SARS-CoV-2 (Fig. 1a), further investigation is required to identify the exact source and other intermediate hosts.

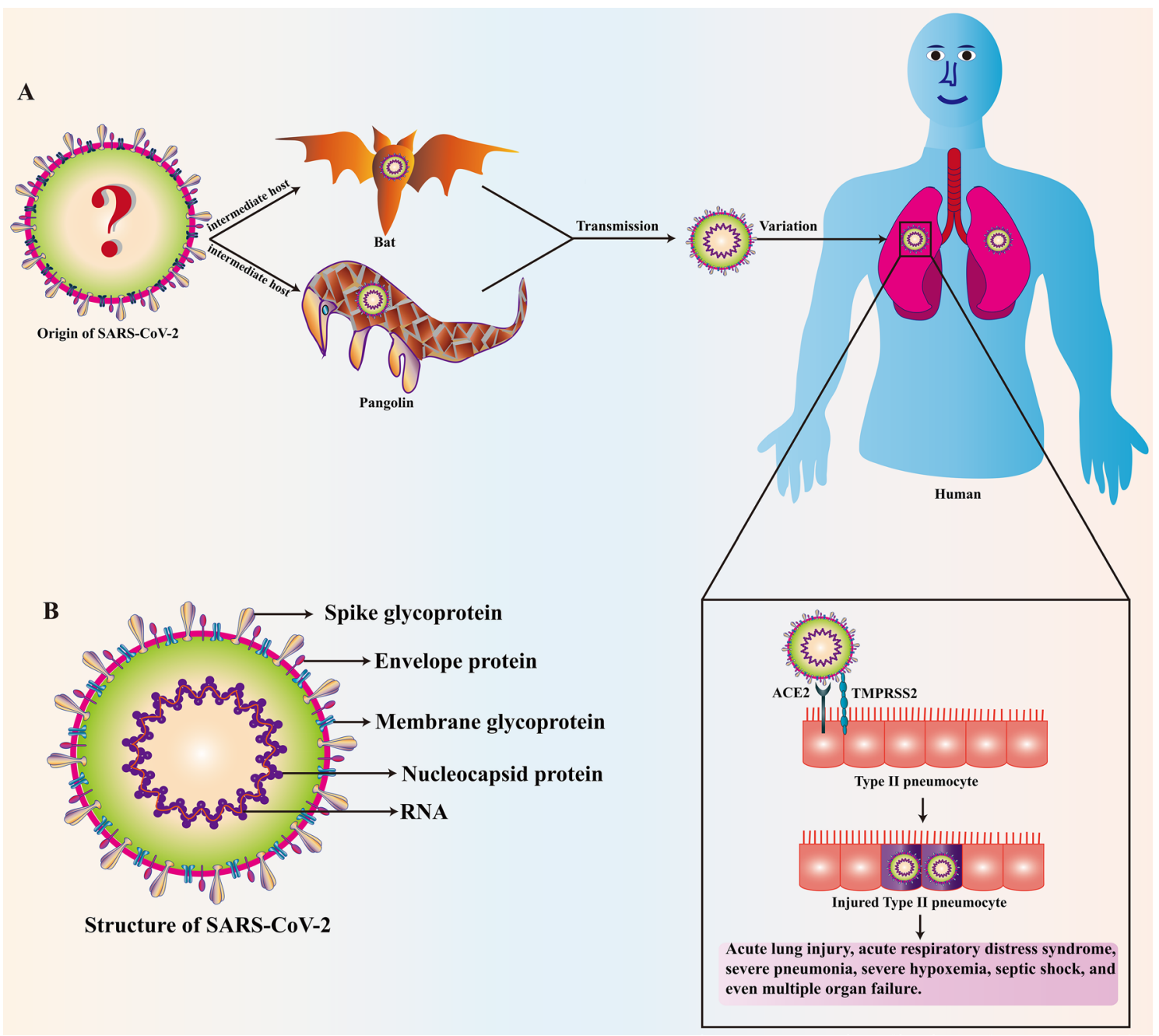

Fig. 1 Basic characteristics and entry of SARS-CoV-2 into the host pneumocyte. a Bats and pangolins are thought to be two of the intermediate hosts of SARS-CoV-2, however, further investigation is required to identify other intermediate hosts. SARS-CoV-2 binds to ACE2 through the spike glycoprotein on the surface of the virus and the spike protein of SARS-CoV-2 is activated by TMPRSS2. The pulmonary alveoli are infected with SARS-CoV-2, leading to injury of the type II pneumocyte. This can lead to acute lung injury, acute respiratory distress syndrome, severe pneumonia, severe hypoxemia, septic shock, and even multiple organ failure. b SARS-CoV-2 consists of the spike glycoprotein, envelope protein, membrane glycoprotein, and nucleocapsid protein. The RNA contains the genetic information that is passed to the next generation of virions which subsequently infect other host cells 


\section{Pathogenesis of COVID-19}

By infecting human bronchial epithelial cells, lung cells, and upper respiratory tract (URT) cells, SARS-CoV-2 can develop into a serious life-threatening respiratory disease, resulting in severe ARDS and permanent lung injury [70, 83]. Studies have found that the host receptor by which SARS-CoV-2 enters is the same as the host receptor for ACE2 [84]. SARS-CoV-2 consists of a spike glycoprotein, membrane glycoprotein, envelope protein, and nucleocapsid protein (Fig. 1b). SARS-CoV-2 binds to ACE2 through the spike glycoprotein on its surface (Fig. 1a, b), which can be modulated by transmembrane protease serine 2 (TMPRSS2) [85-87]. The symptoms of COVID-19 are generally divided into three stages: (1) the asymptomatic stage, which lasts for one to two days after infection, during which the virus attaches to the ACE2 receptor and starts to replicate. Innate immunity is lacking at this stage. (2) The URT infection stage, during which the virus migrates into the respiratory tract, triggering innate immunity. For most SARS-CoV-2 infected people, the infection is limited to URT. (3) The third and final stages involves ARDS and hypoxia, as the virus stresses and damages the alveoli. The alveoli release interferon (IFN), which sends signals to nearby unaffected cells to release antiviral peptides. These signal peptides cause resistance to the virus, and damaged cells release damageassociated molecular patterns, pathogen-associated molecular patterns, and secrete a series of cytokines that activate the innate immune response [88]. Macrophages respond to these signals by releasing more inflammatory factors, causing fluid filling between the capillaries and alveoli. In the process of killing the virus, neutrophils are recruited to the site of infection, possibly damaging healthy lung cells. During this period, the surfactants present in the alveoli are reduced. Phagocytes also release inflammatory cytokines, such as interleukin (IL)-1, IL-2, IL-6, IL-8, IL-12, tumor necrosis factor (TNF)- $\alpha$, granulocyte colony-stimulating factor (G-CSF), transforming growth factor- $\beta 1$ (TGF- $\beta 1$ ), and monocyte chemoattractant protein-1 (MCP-1), which can cause an inflammatory response and subsequent lung infections $[89,90]$. These cytokines also lead to increased levels of procoagulants.

\section{Clinical features of COVID-19}

The most significant feature of the disease is its heterogeneity, as it ranges from asymptomatic infections to inducing critically ill symptoms [91, 92]. The incubation period of COVID-19 is calculated to be two weeks, and the median time is thought to be 4-5 days $[1,93]$. A research report showed that $97.5 \%$ of COVID-19 patients developed symptoms within 11.5 days of SARS-CoV-2 infection [94]. Autopsy results have shown micro-thrombosis in multiple organ systems, such as the lung, heart, and kidney, which indicates that thrombosis precedes multiple organ dysfunction in severe cases [95]. Xu et al. found that patients with severe COVID-19 had respiratory failure and acute bilateral lung infiltration [96]. Hariri et al. further compared SARS-CoV-2 with SARS-CoV and H1N1 influenza and found that $88 \%$ of COVID-19 patients had acute diffuse alveolar damage, which is comparable to $\mathrm{H} 1 \mathrm{~N} 1(90 \%)$ and SARS (98\%). Pulmonary micro-thrombosis was reported in $57 \%, 58 \%$, and $24 \%$ of the SARS-CoV-2, SARS-CoV, and H1N1 infected patients, respectively [97]. In short, the main symptoms of COVID-19 include fever, headache, dry cough, chest tightness, sore throat, adverse gastrointestinal reactions, abdominal pain, diarrhea, hypoxemia, systemic muscle and joint aches, nasal congestion, rhinorrhea, liver damage, acute lung injury (ALI), metabolic acidosis, conjunctival congestion, ARDS, and severe pneumonia [98-100].

\section{Main treatment strategies for COVID-19}

Researchers are continuing to explore various methods to treat COVID-19. At present, large-scale drug screening, indepth exploration of viral pathogenesis, application of rapid detection kits, and anti-inflammatory and antiviral therapies have been widely applied to prevent further spread of the disease [20, 56, 101, 102]. Extracorporeal membrane oxygenation (ECMO) is an invasive mechanical ventilation strategy mainly used to support continuous external breathing and circulation in critically ill patients with critical cardiopulmonary failure [103]. However, these devices are often expensive, and resources of ECMO are limited globally. It is urgent that effective treatments to reduce mortality and improve clinical outcomes are developed, especially for severe and critically ill patients. The main measures to alleviate COVID-19 in patients (especially severe patients) include: (1) plasma therapy for convalescent patients; (2) antiviral drug therapy; (3) immunemediated therapy; (4) glucocorticoid therapy; (5) inhibition of the binding of human cell surface receptor ACE2 protein to the virus; (6) inhibition of key enzymes in the virus; (7) metabolic support and nutrition therapy; (8) stem cell therapy; (9) integrated Chinese and Western medical therapies; (10) probiotic therapy; (11) artificial liver therapy; and (12) lung transplantation [104-112]. In addition, blood purification systems have also been investigated. These studies speed up the screening of effective drugs to prevent mild cases of the disease from developing into severe cases, and improve the treatment regimens for severe and critically ill COVID-19 patients. 


\section{Underlying mechanisms of the MSCs used to treat COVID-19}

Rapid developments in regenerative medicine have led scientists to study and isolate MSCs from different human tissues, and they have been utilized for a variety of purposes such as the repair of lung tissues [113-115]. MSCs can be utilized to treat many common lung diseases, such as ALI [116-118], idiopathic pulmonary fibrosis [119-121], ARDS [122-124], lung cancer [125-127], asthma [128, 129], and chronic obstructive pulmonary disease (COPD) [130, 131]. A schematic diagram of this process is shown in Fig. 2.

Early reports indicated that MSCs could be used to treat various lung diseases by promoting repair and regulating inflammation in the lung [132-134]. While there are differences in the mechanism of different lung diseases, MSCs have shown positive effects in preclinical studies. Recently, clinical studies have found that the cytokine profile of COVID-19 patients undergoes great changes after treatments with MSCs [135-138], which may lead to immune imbalances and multiple lung dysfunctions. The main mechanisms of action for MSCs in the treatment of COVID-19 are shown in Fig. 3.

\section{Differentiation potential}

Under certain conditions, the addition of special inducing factors can guide MSCs to differentiate into nerve, muscle, and epithelial cells, thus proving their differentiation potential into endodermal and neuro-dermal tissues [139]. Previous studies have shown that MSCs may have the ability to transdifferentiate into alveolar epithelial cells $[115,140]$. Furthermore, transplanted MSCs were found to differentiate into respiratory epithelial cells to compensate for the functional alveolar epithelial cell barrier in diseased tissues and improve local damage. Recently, Liu et al. induced the differentiation of hUC-MSCs into type 2 alveolar epithelial cells and transplanted differentiated cells into pulmonary fibrosis mice. They found that differentiated cells could reduce the mortality of bleomycininduced pulmonary fibrosis mice [141]. Therefore, it was determined that MSCs could be applied to treat various lung diseases, including lung injury and inflammation caused by SARS-CoV-2 infection, due to their potential to differentiate into alveolar epithelial cells.

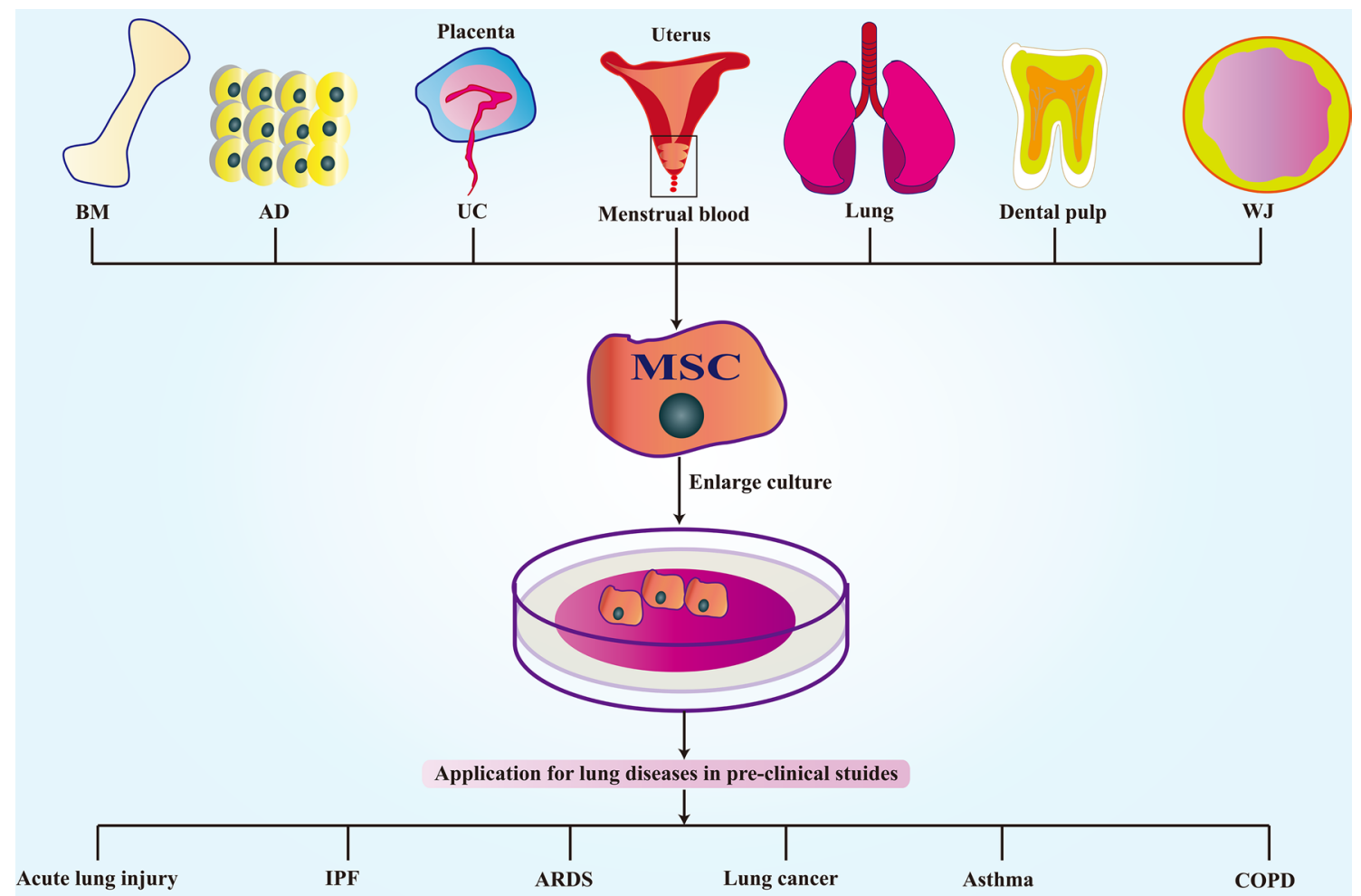

Fig. 2 MSC-based therapies for pre-clinical studies in lung diseases. MSCs can be obtained from most human tissues, including bone marrow (BM), adipose tissue (AD), umbilical cord (UC), Wharton's jelly (WJ), menstrual blood, placenta, dental pulp, and lung. MSCs can treat many lung diseases, such as acute lung injury, idiopathic pulmonary fibrosis (IPF), acute respiratory distress syndrome (ARDS), lung cancer, asthma, and chronic obstructive pulmonary disease (COPD) 
Fig. 3 The main mechanisms of action for MSCs in the treatment of COVID-19. The main mechanisms by which MSCs exert their effect in the treatment of lung-related diseases is through their differentiation potential, immune regulation, secretion of anti-inflammatory factors, migration and homing, anti-apoptotic properties, antiviral effects, and through extracellular vesicles

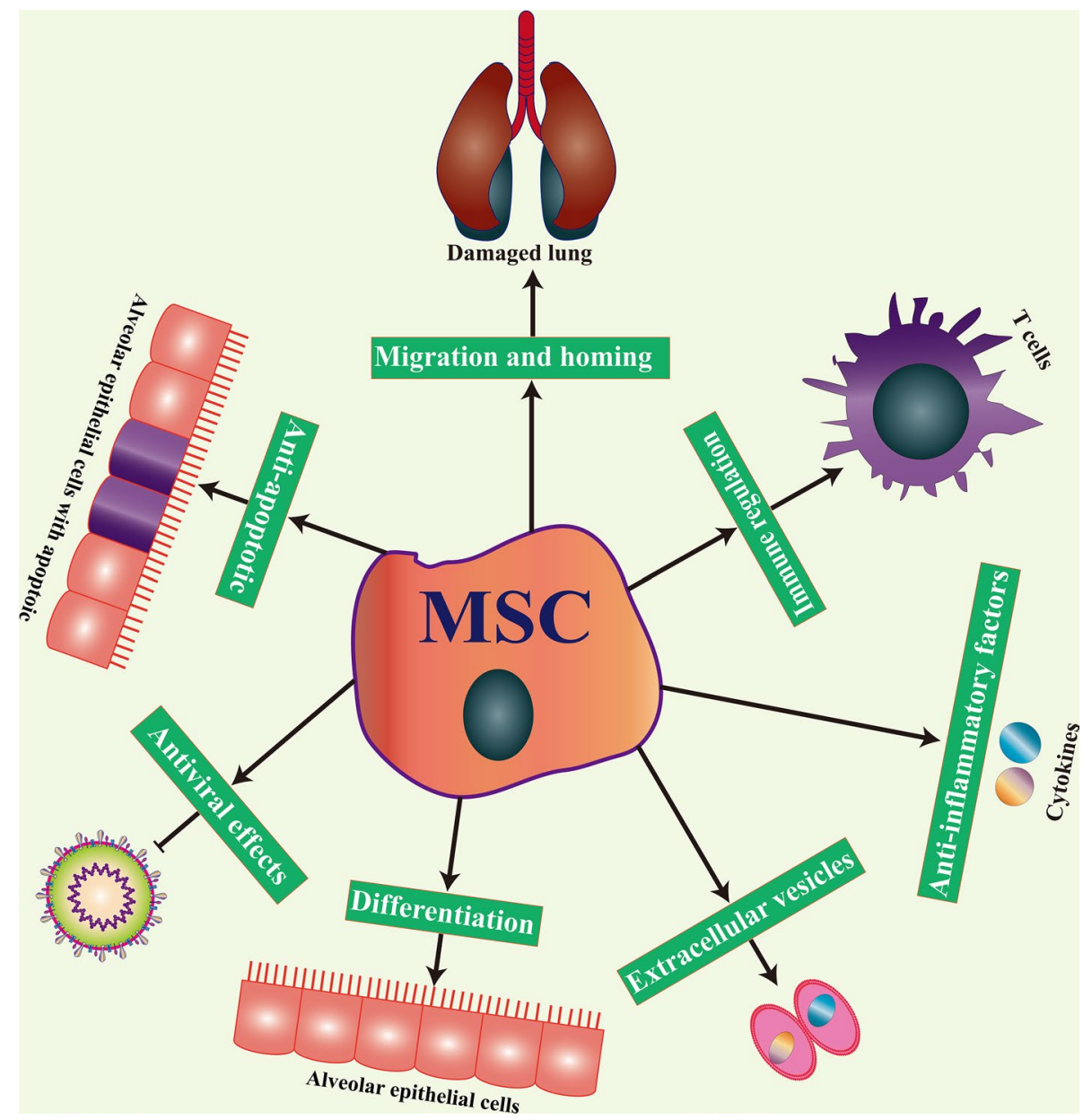

\section{Immune regulation}

The role of MSCs in immune regulation has been extensively studied. MSCs can regulate both innate and adaptive immunity by interacting with various immune cells $[56,58$, 142, 143]. MSCs can also regulate innate immune responses by targeting DCs, natural killer (NK) cells, innate T helper 17 cells, neutrophils, mast cells, and macrophages [56]. Due to the immune escape mechanism of SARS-CoV-2, the virus partly evades the recognition and attack of the innate immune system, causing adaptive immunity to play a key role. MSCs mainly regulate adaptive immunity by targeting $\mathrm{T}$ lymphocytes, B lymphocytes, antigen-presenting cells (APCs), DCs, NK cells, and regulatory T cells (Tregs) [58]. In addition, the local immunity of the lung is mediated by $\mathrm{CD} 4^{+} \mathrm{T}$ cells and $\mathrm{CD} 8^{+} \mathrm{T}$ cells, which can quickly kill foreign viruses during infection [144], implying that the adaptive immunity regulation mechanism by MSCs may be applied in the treatment of COVID-19. Although the human body's dual immune system can mostly prevent the virus from invading, SARS-CoV-2 has an escape mechanism. After MSCs are injected into the body, the immune regulation mechanism allows additional mobilization of various immune cells, which further prevents the invasion of SARS$\mathrm{CoV}-2$. As a response to inflammatory mediators, MSCs mainly produce a variety of soluble factors that regulate the immune response, including PGE2, TGF- $\beta 1$, indoleamine 2,3-dioxygenase (IDO), nitric oxide (NO), HGF, and IL-10 [143].

\section{Secretion of anti-inflammatory factors}

The inhibition of inflammation is another important function of MSCs. MSCs secrete a variety of soluble factors through paracrine action, collectively called secretory bodies. Studies have found that many inflammatory factors were increased in the blood of COVID-19 patients, such as IFN- $\gamma$, IFN inducible protein-10, and MCP-1. In addition, the concentration of inflammatory factors, such as G-CSF, MCP-1, and TNF- $\alpha$, in intensive care unit (ICU) patients have been shown to be significantly higher than in non-ICU patients [145]. Several studies have shown that the therapeutic effect of MSCs is mainly mediated by the secretion of paracrine factors, including growth factors, chemokines, and cytokines [146, 147]. The cytokine storm in patients with severe COVID-19 causes the release of nitric oxide, 
which affects the normal contraction and diastolic functions of the blood vessels, resulting in hypotension, multiple organ hypoxia, and ARDS [148, 149]. SARS-CoV-2 causes a cytokine storm and secretes high levels of pro-inflammatory cytokines, such as IL-1 $\beta$, IL-1RA, and IL-2, in the lungs. As well as, IL-6, IL-7, G-CSF, IFN, TNF, PI3-K/ AKT, Rac1, alveolar cavity neutrophils, and infiltration of macrophages [145, 150, 151]. Ellison-Hughes et al. summarized how MSCs potentially alleviate damage caused by COVID-19-induced cytokine storms, and explored how MSC transplantation facilitated the reduction of long-term complications in COVID-19 patients, including lung injury repair and partial functional lung cell regeneration [152]. In addition, our group has found that menstrual blood-derived MSCs improve lung function by secreting anti-inflammatory cytokines both in ALI and pulmonary fibrosis mouse models $[153,154]$. The main mechanism of MSC-based therapy for COVID-19 is mediated by the production of anti-inflammatory molecules and reductions in the secretion of inflammatory factors. In summary, inflammatory factors are reduced, and anti-inflammatory factors are increased by MSC infusion. Therefore, the anti-inflammatory effects of MSCs can be utilized in the treatment of COVID-19.

\section{Migration and homing}

Migration and homing are unique characteristics of MSCs. Although not a direct effect of MSCs, their chemotaxis enables them to target injured lung tissues $[155,156]$, allowing a further exertion of their therapeutic effects. MSCs can migrate to the site of injury after intravenous or local injection. Migration and homing is a multi-step process that includes three different stages: (1) direct administration or cell recruitment and entering the blood circulation; (2) extravasation through the concentration gradient of lymphocytes near the lesion; and (3) migration to the damaged interstitium of the lung [157]. This process is mainly induced by chemokines released from injured or inflamed lung tissues, which triggers the migration and homing of MSCs [156, 158]. G-CSF is a common pharmacological agent used to induce mobilization, which acts through the expansion of the medullary compartment, activity of neutrophil elastase, release of cathepsin G, and reduction of stromal cell-derived factor-1 (SDF-1) levels. Stabilization of hypoxia-inducible factor-1 $\alpha(\mathrm{HIF}-1 \alpha)$ increases mobilization by sinus-shaped vasodilatation caused by an increase in VEGF levels. In short, the main factors for MSC migration and homing include SDF-1, CXCR4, G-CSF, HIF-1 $\alpha$, PGE2, peroxisome proliferator-activated receptor (PPAR)- $\gamma, \mathrm{MCP}-1, \mathrm{CXCR} 7$, CCR2, $\alpha 4 / \beta 1$ integrin, and CD44 molecules [158]. In addition, MSCs can recognize some endothelial cell adhesion molecules, including palmitate $\mathrm{G}$ protein, vascular cell adhesion molecule-1, and intercellular adhesion molecule-1, thereby mediating migration and homing.

\section{Anti-apoptotic properties}

Apoptosis is a defense mechanism of the host against the source of infection, and it plays a vital role in the interactions between the host and pathogen. MSCs, however, have the ability to resist apoptosis. Studies of SARS-CoV-2 patients have observed different degrees of apoptosis during the viral infection stage [159]. Lymphopenia caused by immune cell failure due to $\mathrm{T}$ cell exhaustion and apoptosis has also been observed in the same patient population [160]. Therefore, it is particularly important to effectively control apoptosis in COVID-19 patients. MSCs inhibit cell apoptosis resulting from hypoxia, chemical stimulation, mechanical damage, and radiation. The anti-apoptotic effect of MSCs has been fully demonstrated in cardiac ischemia and neurological and pulmonary diseases [161]. Bernard et al. found that HGF and KGF released by MSCs protected alveolar epithelial cells from apoptosis by increasing B-cell leukemia/lymphoma-2 (Bcl-2) expression and inhibiting HIF-1 $\alpha$ expression [162]. In hypoxia-induced apoptosis, MSCs induced the expression of several factors, including VEGF, TGF- $\beta 1$, and HGF, to reduce the apoptosis of endothelial cells. The anti-apoptotic properties of MSCs against lung diseases mean that MSCs could potentially be used as a treatment for COVID-19.

\section{Antiviral effects}

Antiviral effects are another feature of MSCs. MSCs inhibit virus replication, virus shedding, and virus-induced lung epithelial cell damage [163]. IDO [164] and antimicrobial peptide LL37 [165] produced by MSCs have been shown to inhibit influenza virus replication through viral membrane degradation. Khatri et al. studied the swine influenza virus pneumonia model and showed that intra-tracheal administration of MSC-derived EVs could effectively reduce virus replication in lung epithelial cells [163]. Additional studies have shown that SARS-CoV2 enters cells through the widely distributed ACE2 receptors, including alveolar and capillary endothelial cells. RNA-sequence analysis has found that transplanted MSCs are ACE2 negative and can therefore resist SARS-CoV-2 infection [166]. In addition, MSCs retained their immunomodulatory potential, which supports their potential applicability for treating COVID19 [65]. Recently, Avanzani et al. demonstrated the role of SARS-CoV-2 infection in MSCs derived from various human tissues. These findings support the use of MSCs as a potential method by which to downregulate immune over-activation in COVID-19 patients and reduce fibrosis in patients recovering from acute SARS-CoV-2 infections [66]. The mechanisms by which MSCs inhibit the replication 
and infection of SARS-CoV-2, however, are unknown and require further investigation.

\section{MSC-EVs}

EVs are mainly divided into extracellular bodies, microvesicles, and apoptotic bodies [167]. As a medium for cell-tocell communication, EVs play a vital role in cell-to-cell transmission under pathophysiological conditions, including the transmission of RNAs, antigen presentation, tumor immune regulation, and drug loading [168-170]. This strategy bypasses most of the safety issues related to cell therapy, such as cancer cell contamination and cell proliferation hazards. Recent studies have shown that EVs derived from MSCs can improve bronchopulmonary dysplasia, ARDS, COPD, idiopathic pulmonary fibrosis, COVID-19, and pulmonary hypertension [171-173]. Morrison et al. showed that MSCs regulate macrophages in ALI through EV-mediated mitochondrial transfer [174]. Functional mitochondria transferred through MSC-EVs enhanced the mitochondrial function of primary human alveolar cells and their ability to repair lung injury [163]. EVs can reduce pulmonary inflammation by reducing the recruitment of neutrophils and macrophages and the level of MIP-2 [175]. At the same time, EVs can reduce pulmonary edema and endothelial permeability. In a mouse model of lung ischemia/reperfusion injury, the anti-apoptotic molecule miR-21-5p was found to be the main link to the protective effect of the MSC-EVs [176]. Specifically, exogenous miR-21-5p reduces lung tissue oxidative stress-induced apoptosis by targeting the phosphatase and tensin homolog (PTEN) and programmed cell death 4 (PDCD4) [176]. These findings strongly support the use of MSC-derived EVs as a treatment for COVID-19.

\section{Clinical studies of MSC transplantation to treat COVID-19}

At present, there are no effective treatments available for COVID-19 patients who are classified as critically ill. However, stem cell transplantation is an emergency treatment method that could be used to address this, and is currently being tested in clinical trials in research institutions around the world [177-179]. As of Nov 17, 2021, according to Clinicaltrials.gov (https://www.clinicaltrials.gov/; search for "COVID-19" and "mesenchymal stem cell"), a total of 74 MSCs are currently being verified in clinical trials to treat COVID-19 (Table 1). Among these MSC clinical trials (Table 1), 22 were using UC-MSCs, 15 AD-MSCs, and $11 \mathrm{BM}-\mathrm{MSCs}$. There were also $7 \mathrm{WJ}, 2$ dental pulp, 1 cord blood, 1 menstrual blood, 1 placental, and 1 mucosalderived MSC clinical trials. In addition to those using known sources for the MSCs, there were also 14 clinical trials using
MSCs from unknown tissue sources. At present, UC, BM, and $\mathrm{AD}$ are the major sources of MSCs used in the clinical trials for the treatment of COVID-19. Most trials were in their early stages, as 19 were phase 1,25 were phase $1 / 2,24$ were phase 2,1 was a phase $2 / 3$ combined trial, 1 was phase 3 , and 4 were unspecified.

Since most of these clinical trials are ongoing, the available clinical research results are currently limited. Leng et al. used MSCs to treat COVID-19 patients [180] and investigated the inflammation, immune function, and adverse reactions of seven patients within 14 days after MSC transplantation. Expression of TNF- $\alpha$ was reduced, and the expression of IL-10 was enhanced. They further reported the absence of any adverse events and concluded that MSCs effectively ameliorated the functional outcomes of all seven patients. In addition, our group studied the therapeutic effects of menstrual blood-derived MSCs in treating COVID-19 in a multicenter, open-label, nonrandomized, parallel-controlled exploratory trial [181]. The mortality of patients in the MSC group was significantly lower $(7.69 \%$ in the MSC group and $33.33 \%$ in the control group). The dyspnea and $\mathrm{SpO} 2$ significantly improved after MSC infusion on days 1, 3, and 5. Chest imaging results of the experimental group also showed improvement within 1 month of the MSC treatment. The incidence of most adverse events did not differ between the MSC and control groups [181]. Another study conducted by Meng et al. included 18 patients with moderate to severe COVID-19, nine of whom received UC-MSC infusion therapy [182]. From their results, two patients who received UC-MSCs experienced transient facial flushing and fever $12 \mathrm{~h}$ after infusion, and one patient experienced transient hypoxia. Recently, the same group conducted a phase 2 study and found that when compared with the placebo group, UC-MSCs significantly decreased the proportion of solid component lesion volume [183]. Lanzoni et al. conducted a double-blind, phase $1 / 2$ a randomized controlled trial in which 24 subjects receiving UC-MSC treatment were followed up for COVID-19 and ARDS for 1 month [184]. They found that the UC-MSC infusion consistently and effectively reduced a group of inflammatory cytokines related to COVID-19 "cytokine storms", thus improving patients' survival and recovery time [184]. Shu et al. studied the possible impact of intravenous UC-MSCs on COVID-19 patients and showed that the transplantation of human UC-MSCs shortened the time for clinical improvement when compared to the placebo group. The incidence of critically ill progression after UC-MSC treatment was 0 , and the 28-day mortality rate was 0 . In the control group, four critically ill patients were treated with invasive ventilation, of which 3 died, and the 28-day mortality rate was $10.34 \%$. At the same time, the clinical symptoms of 


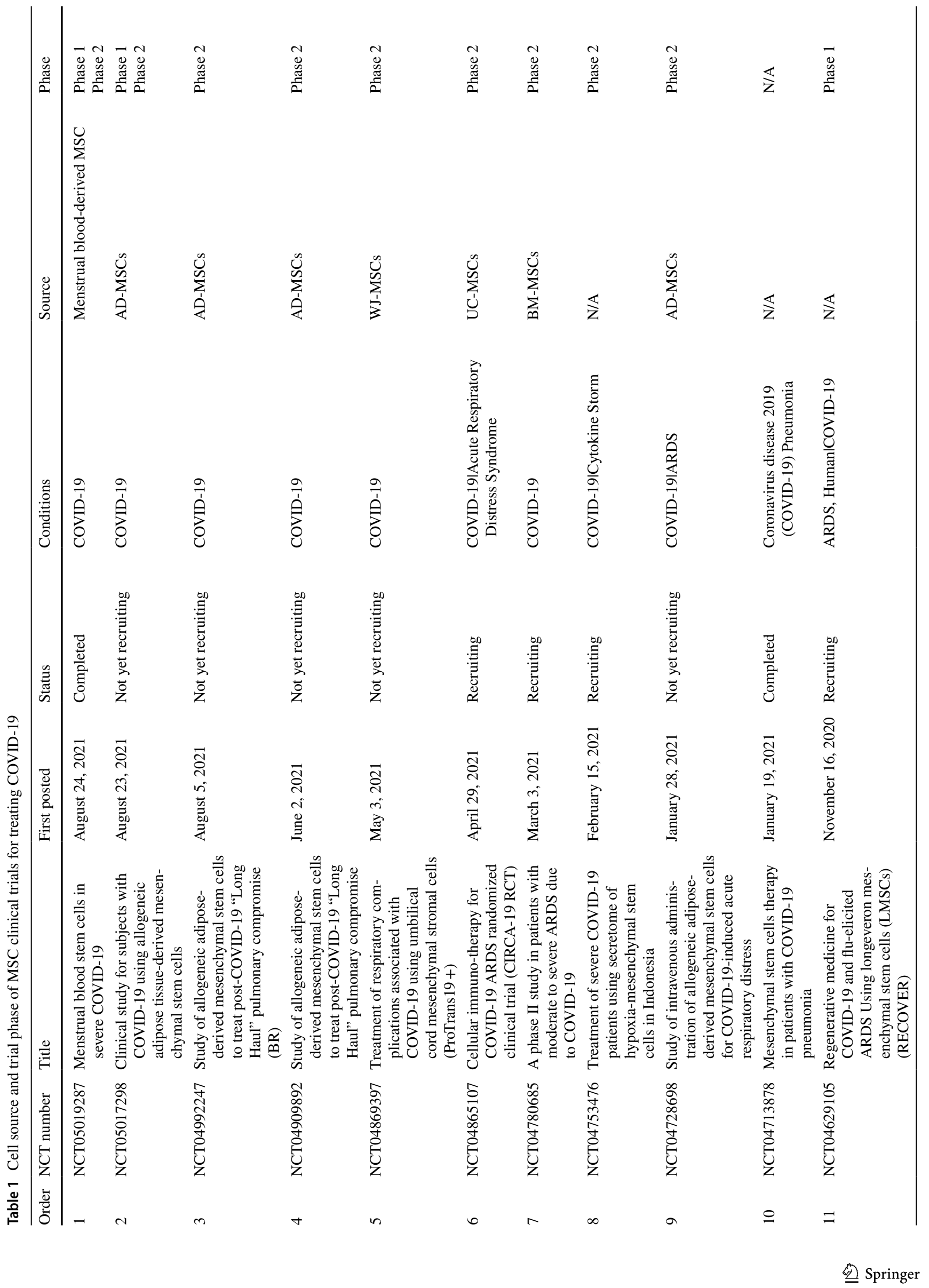




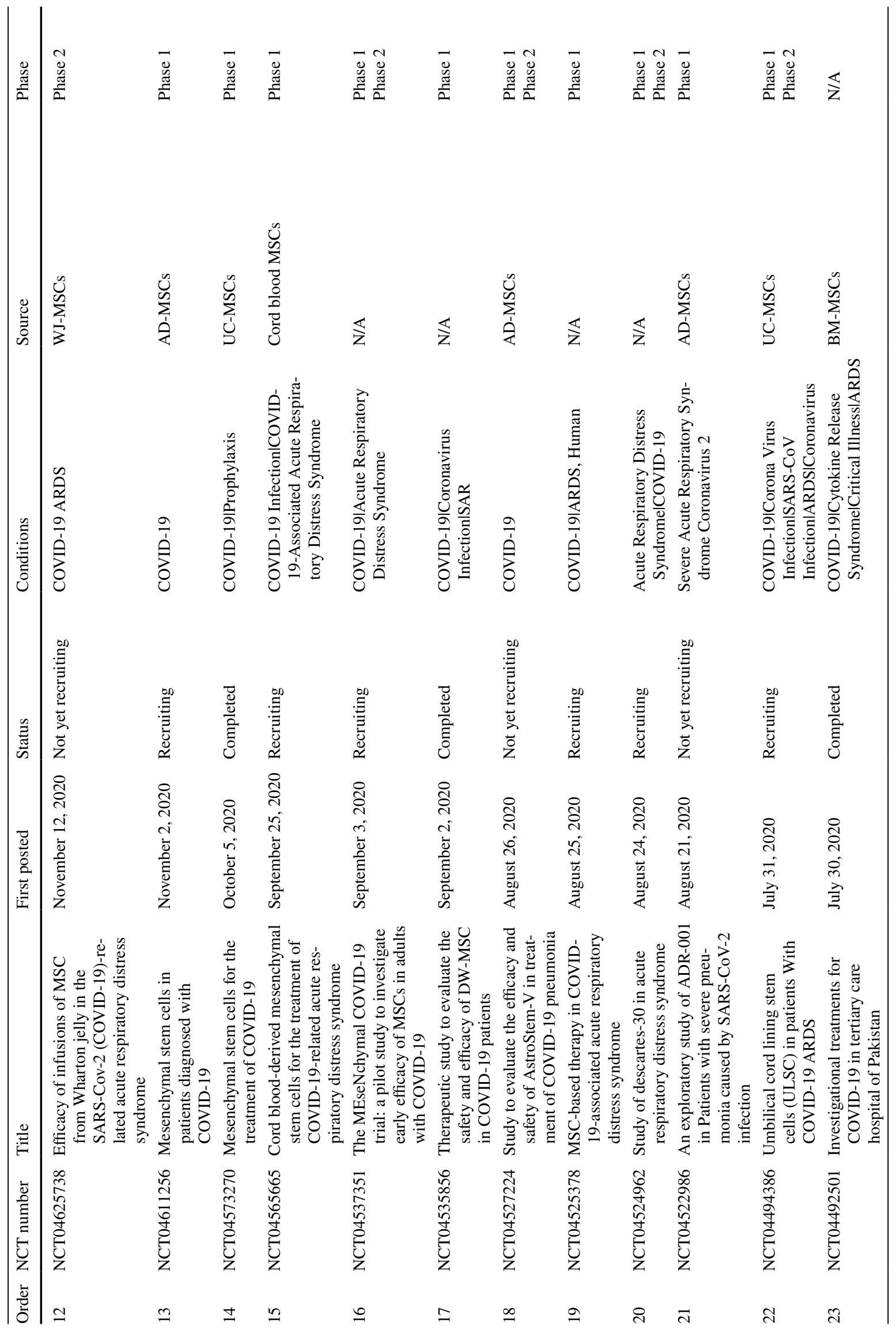




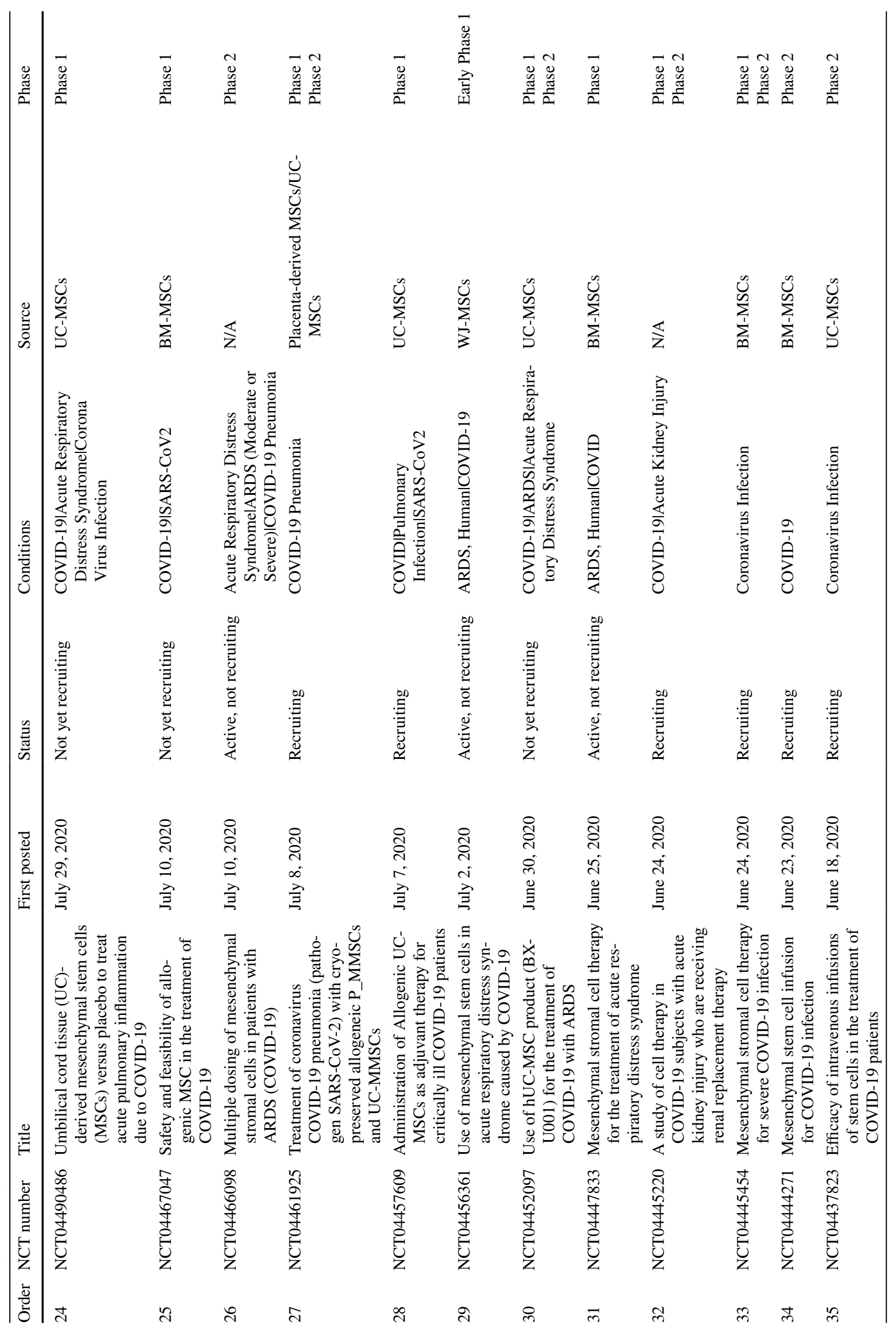




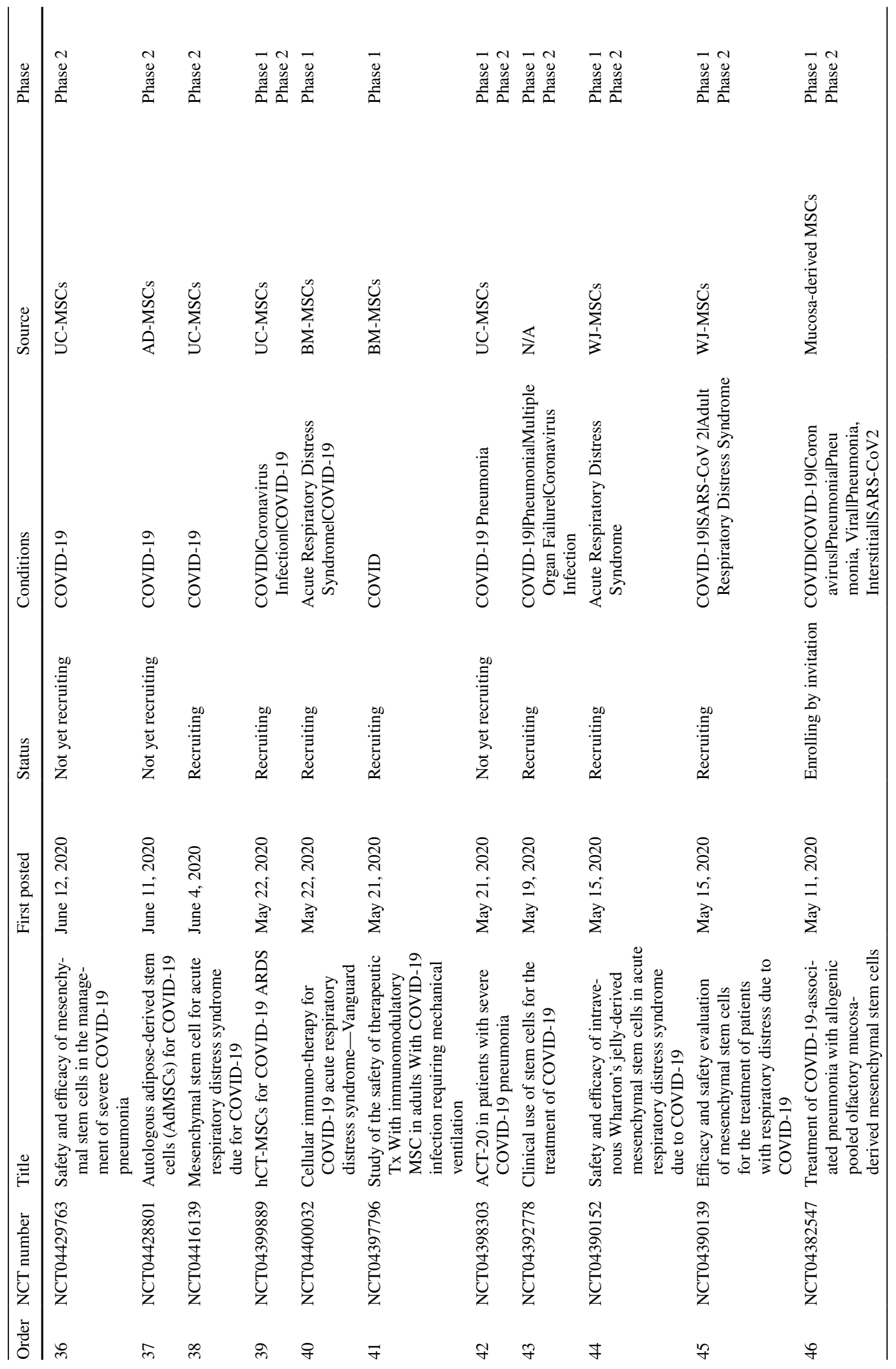




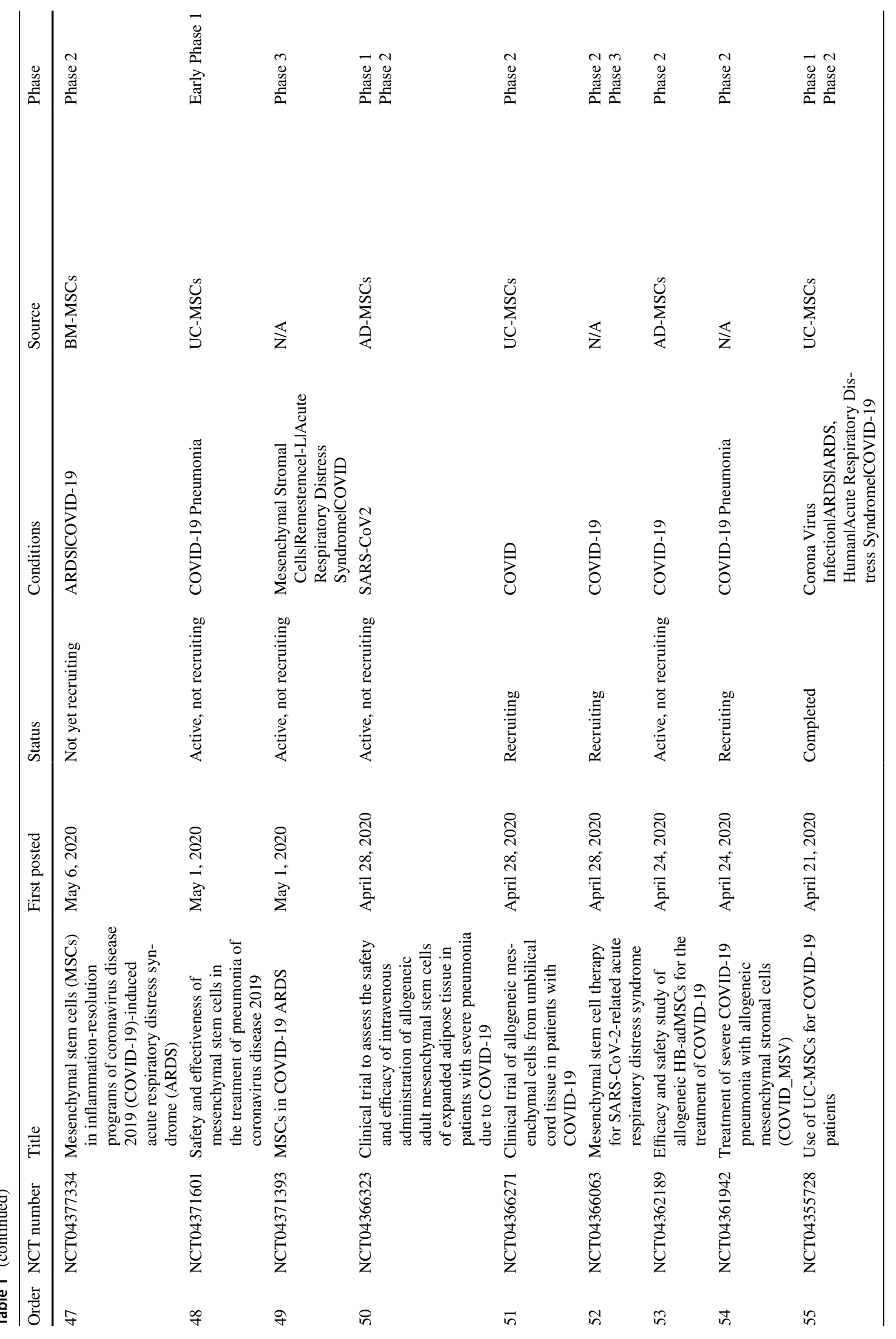




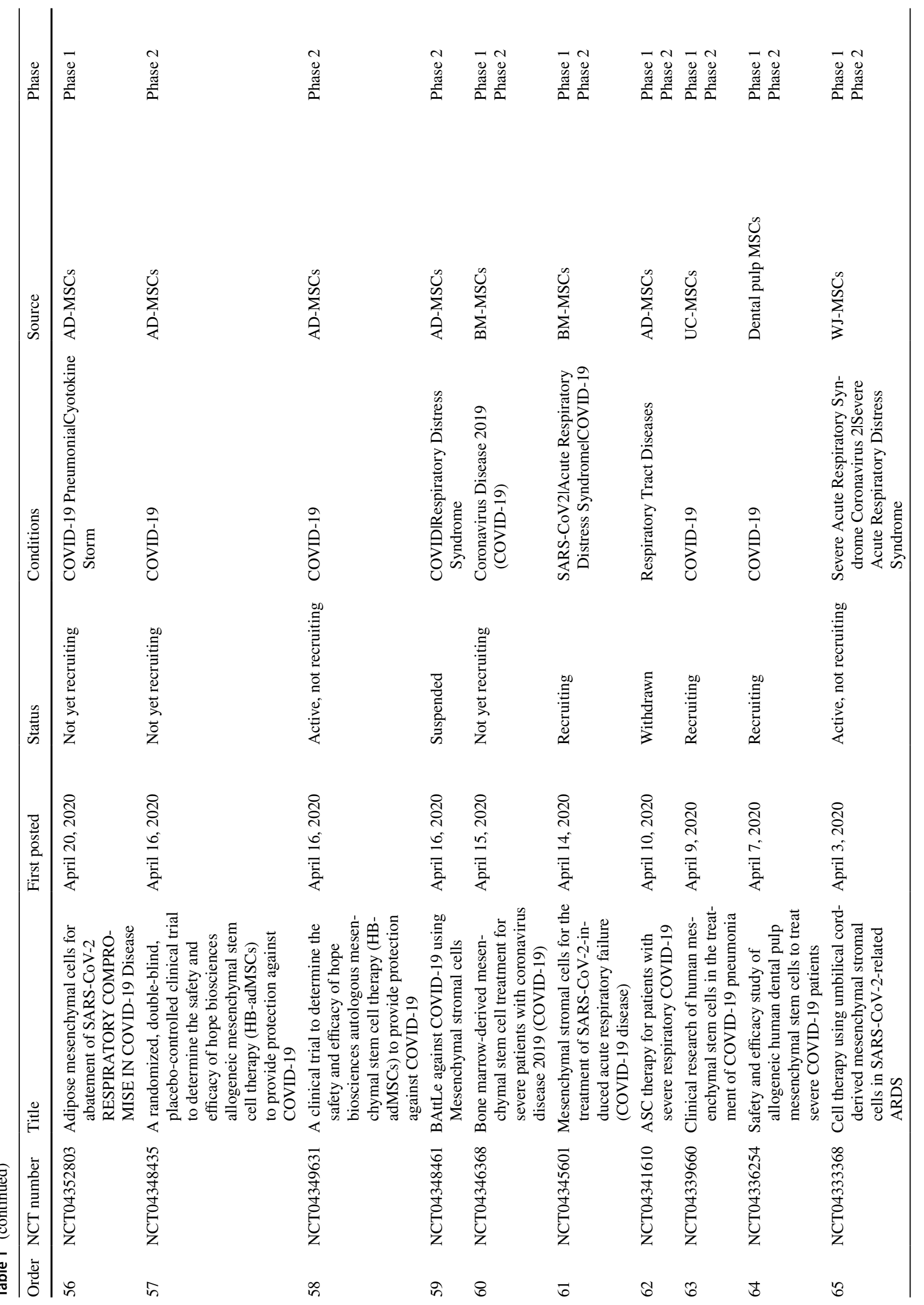




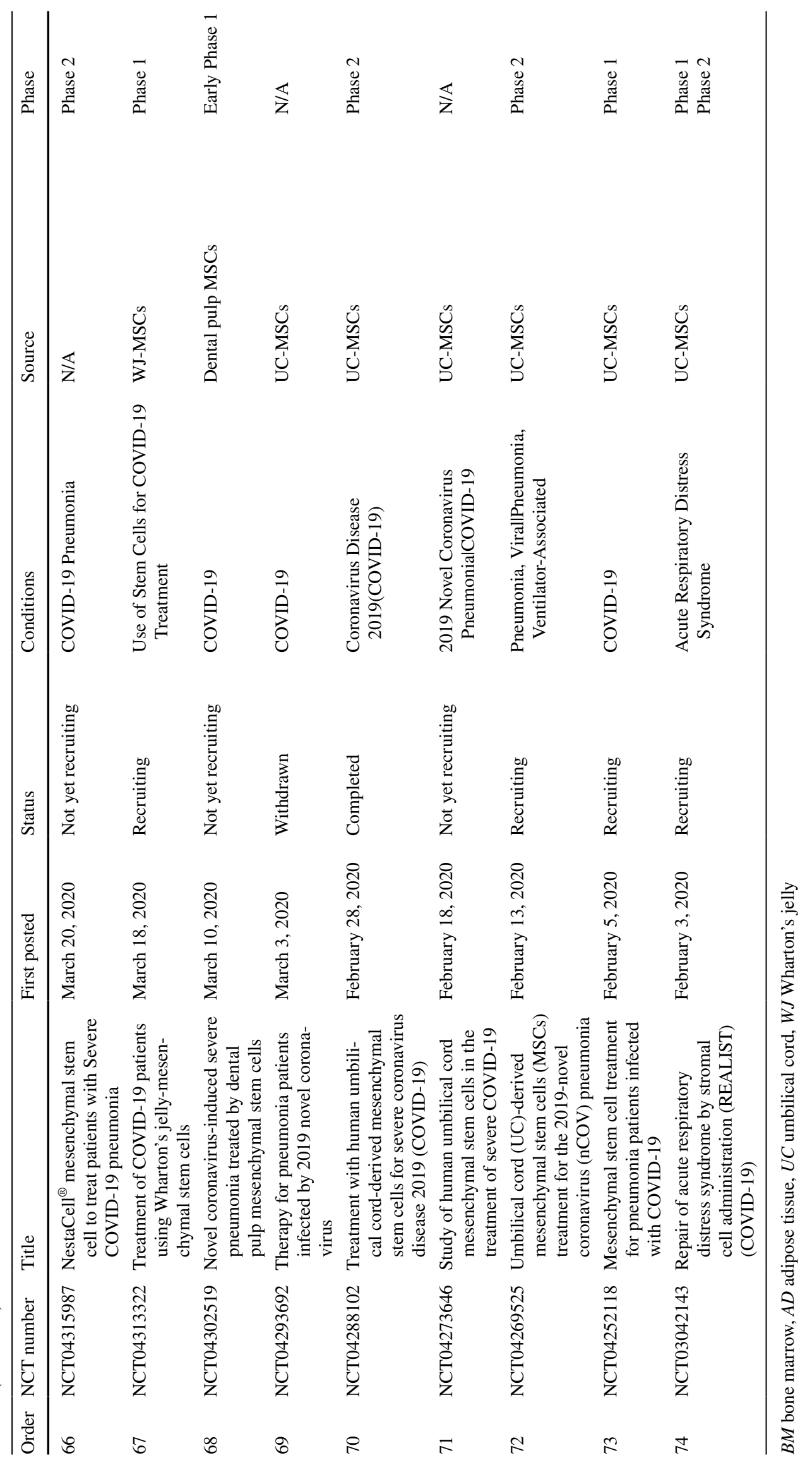


fatigue, weakness, and respiratory distress were significantly reduced after UC-MSC treatment [185]. SánchezGuijo et al. demonstrated the safety of AD-MSCs with the transplantation of $1 \times 10^{6} / \mathrm{kg}$ of AD-MSCs $1-3$ times in 13 patients with severe COVID-19 [186]. The study found that the clinical symptoms of 9 patients (70\%) improved at a median follow-up of 16 days after the first AD-MSC administration. Feng et al. reported that the mortality rate of COVID-19 patients was $6.25 \%$ after UC-MSC infusion. The estimated cytokine levels changed within the normal range, the radiological appearance (ground glass opacity) was improved, and the lymphocyte count and lymphocyte subpopulation $\left(\mathrm{CD} 4^{+} \mathrm{T}\right.$ cells, $\mathrm{CD} 8^{+} \mathrm{T}$ cells, and NK cells) counts were restored after transplantation [187]. Hashemian et al. proved that no serious adverse reactions occurred $24-48 \mathrm{~h}$ after transplantation of the UC-MSCs or placental MSCs [188]. They further observed that $48-96 \mathrm{~h}$ after the first infusion in 7 patients, dyspnea eased and $\mathrm{SpO} 2$ increased. Of these 7 patients, 5 were discharged from the ICU within 2-7 days (average of 4 days). The serum levels of the TNF- $\alpha$, IL- 8 , and $\mathrm{C}$-reactive protein (CRP) were significantly reduced in all six survivors. The six survivors had no symptoms of dyspnea 60 days post infusion. The radiological parameters of the lung CT showed clear signs of recovery [188].

Clinical data increasingly show that "not all MSCs are equal" as MSCs from different tissues express different factors at different levels and have different functions (Table 2). However, regardless of the MSC type, they were all found to exert a significant improvement in lung function or reduced mortality when intravenously transplanted. Although there are many types of MSC injection, the most popular method is intravenous infusion. When compared with different sources of MSC-based therapies in COVID-19, the initial results mainly rely on improving lung function, serum indexes, and inflammation indexes. Currently, there is still no systematic contrast regarding treatment differences with various MSCs. For example, menstrual blood MSCs were used, and a total of $9 \times 10^{7}$ cells showed a rapid improvement in breathing difficulties [181]. AD-MSCs were used in a total of $1-3 \times 10^{6} /$ $\mathrm{kg}$ cells to treat COVID-19 [186]. The UC-MSCs used a range from a total of $9 \times 10^{7}$ cells [182] to a total of $4 \times 10^{8}$ cells [187]. Generally, MSCs should be injected 2-4 times to persistently exert their function. In addition to the above clinical studies, some case reports have shown that MSCs (including UC-MSCs, menstrual blood MSCs, and WJ-MSCs) are a promising method for the treatment of COVID-19, especially critically ill patients [189-192]. Although these preliminary clinical results are encouraging, more clinical data are required to further clarify the underlying mechanisms and potential targets to improve clinical applications.

\section{Current challenges for MSC-based COVID-19 therapies}

Currently, there is a large amount of active clinical research occurring in relation to MSCs for the treatment of various diseases. In particular, the clinical research of MSCs for the treatment of COVID-19 has seen explosive developments. However, in addition to the evaluation of the therapeutic effects of MSCs, more in-depth problems require clarification [193]. The main clinical challenges relating to the use of MSCs to treat COVID-19 are presented in Fig. 4.

First, thrombosis is common in COVID-19, particularly in critically ill patients [194, 195]. COVID-19-specific coagulopathy is caused by increased levels of fibrinogen, von Willebrand factor (vWF), fibrin degradation product, and D-dimer in the blood [196]. SARS-CoV-2 infection induces an inflammatory process called immuno-thrombosis, which activates the interaction of monocytes and neutrophils with platelets and the coagulation cascade, resulting in the formation of intravascular thrombi in small and large blood vessels [196, 197]. During immuno-thrombosis, neutrophils and monocytes can secrete tissue factors and regulate the extracellular nucleosomes to degrade endogenous anticoagulants, thereby promoting inflammation-induced coagulation activation. When immuno-thrombosis is not controlled, it leads to the unregulated activation of the coagulation cascade, which in turn leads to micro-thrombosis and inflammation, creating a positive-feedback-like cycle, which eventually may develop into thrombosis (thrombotic inflammation) and diffuse intravascular coagulation [198]. Thus, thromboprophylaxis and immuno-thrombosis must be monitored in hospitalized COVID-19 patients in the absence of contraindications. Different MSC products show different levels of high procoagulant tissue factor and may have adverse effects on the immediate blood-mediated inflammatory response (IBMIR). Appropriate strategies for evaluating and controlling blood compatibility and optimizing cell delivery are critical for the development of safer and more effective MSC therapies [199].

Second, we should emphasize that due to the unique nature of the COVID-19 outbreak and the ethical restrictions on treating severe COVID-19 patients, not all clinical trials used a standard design. From the perspective of safety and effectiveness, the clinical use of autologous MSCs is the best method to treat COVID-19. However, the production of a clinically relevant number of MSCs requires a significant amount of time, which is not always the case in the current COVID-19 emergency. A large number of MSCs are urgently needed, and the corresponding quality of MSCs must also be strictly controlled.

Third, there is concern regarding the use of fresh and frozen MSCs due to their different therapeutic roles. Moll 


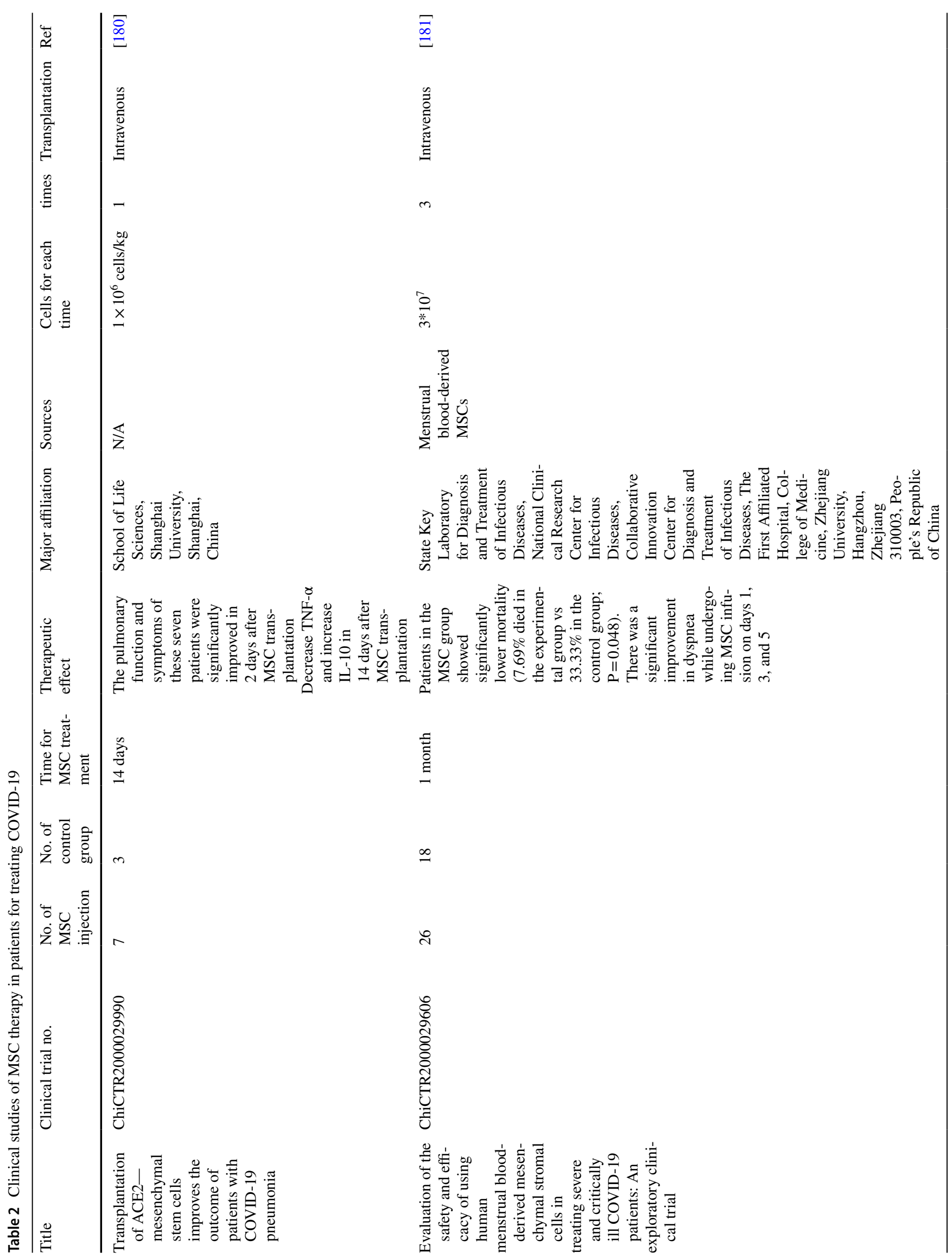


142 Page 18 of 33

L. Chen et al.

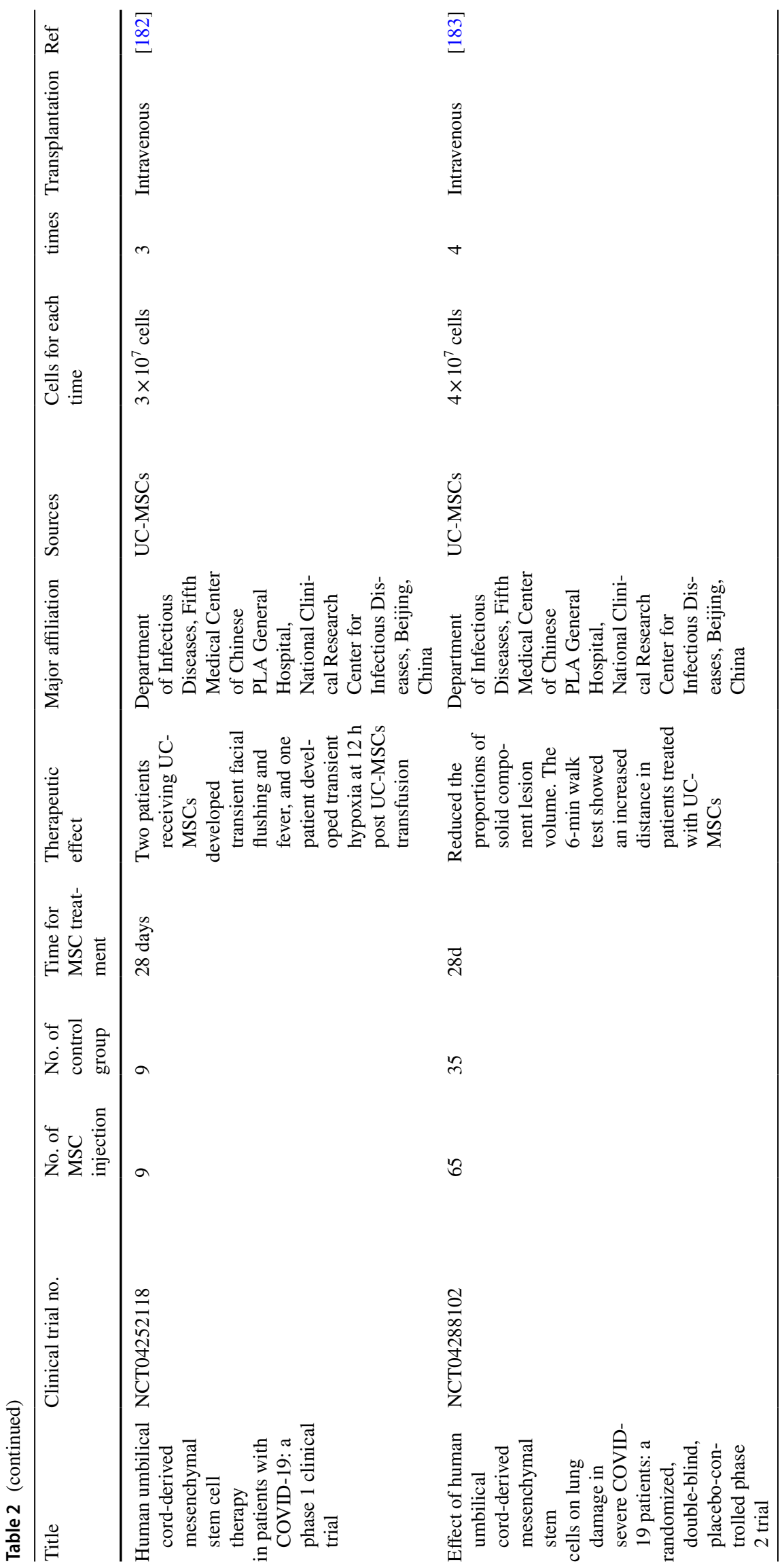

Springer 


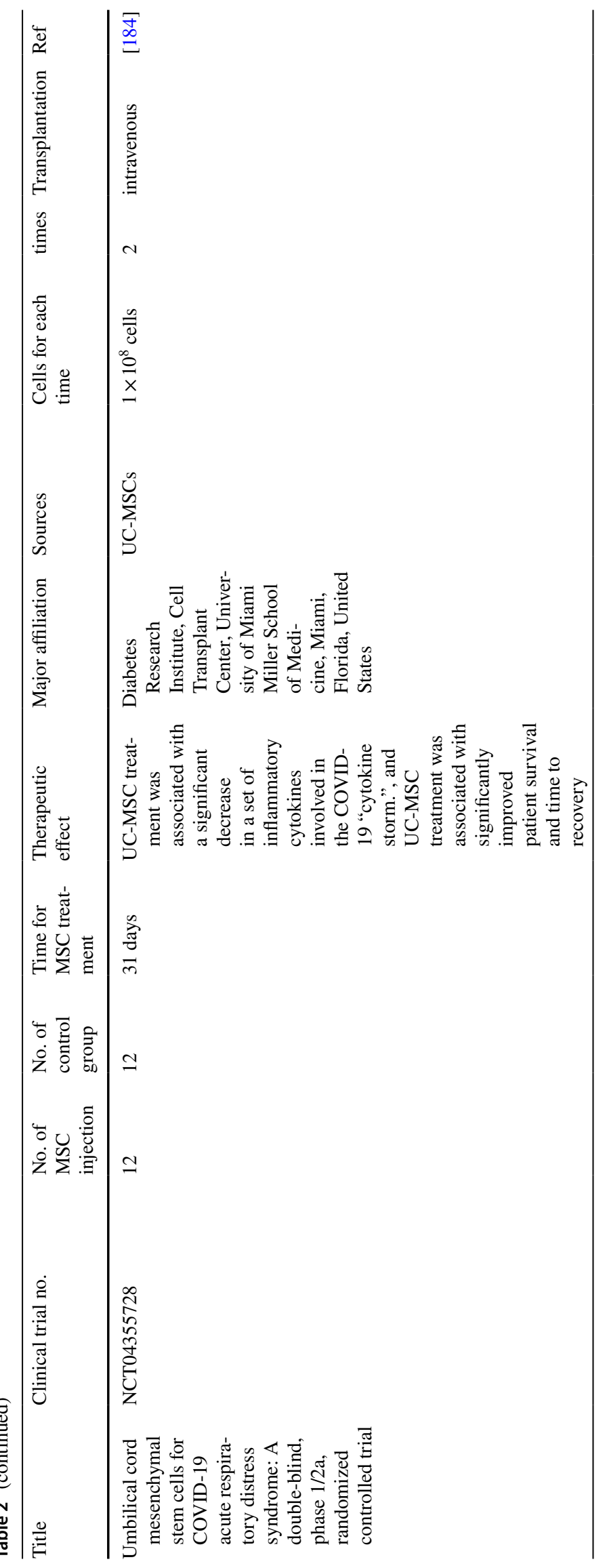




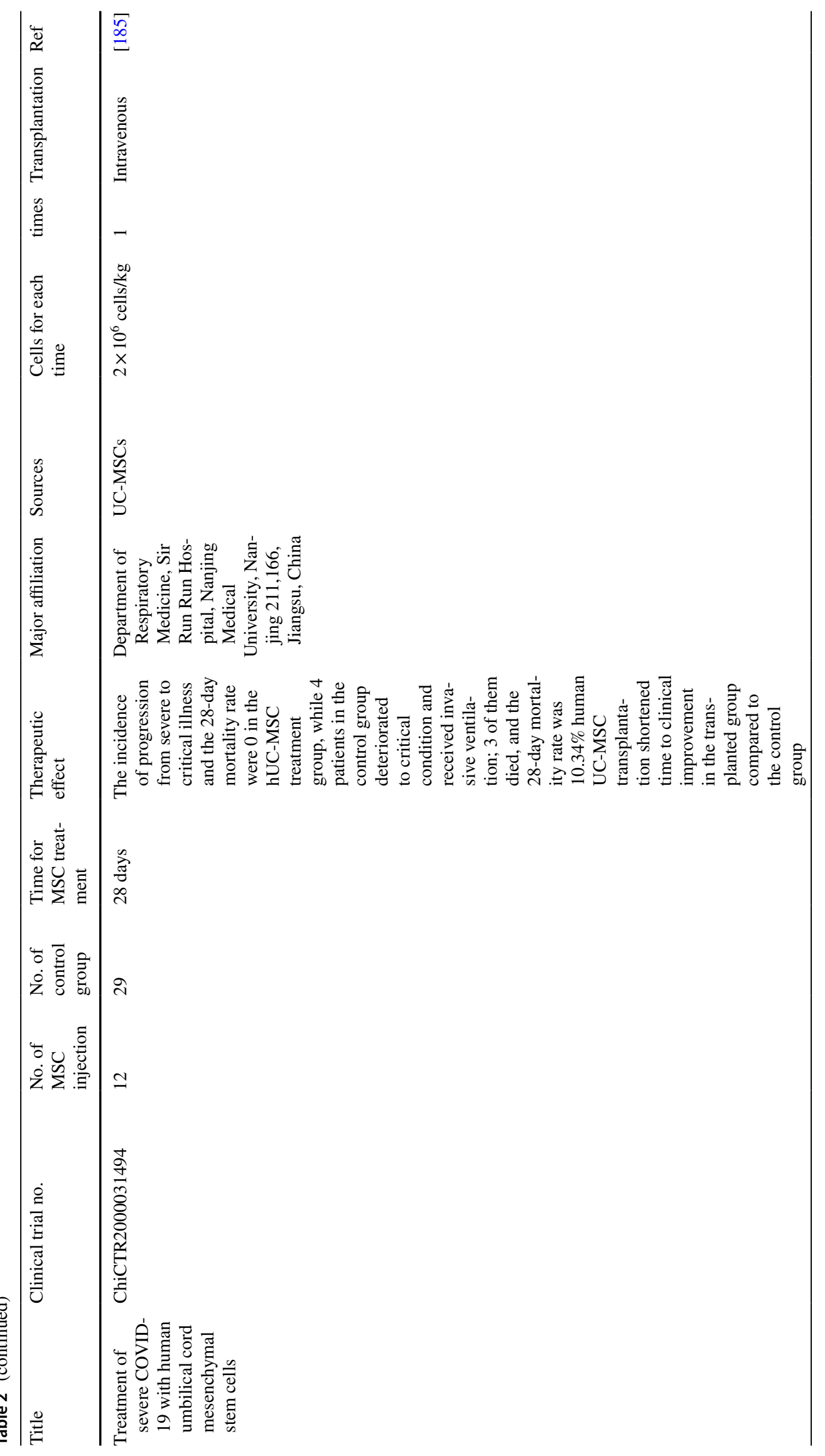


Mesenchymal stem cell-based treatments for COVID-19: status and future perspectives for...

Page 21 of $33 \quad 142$

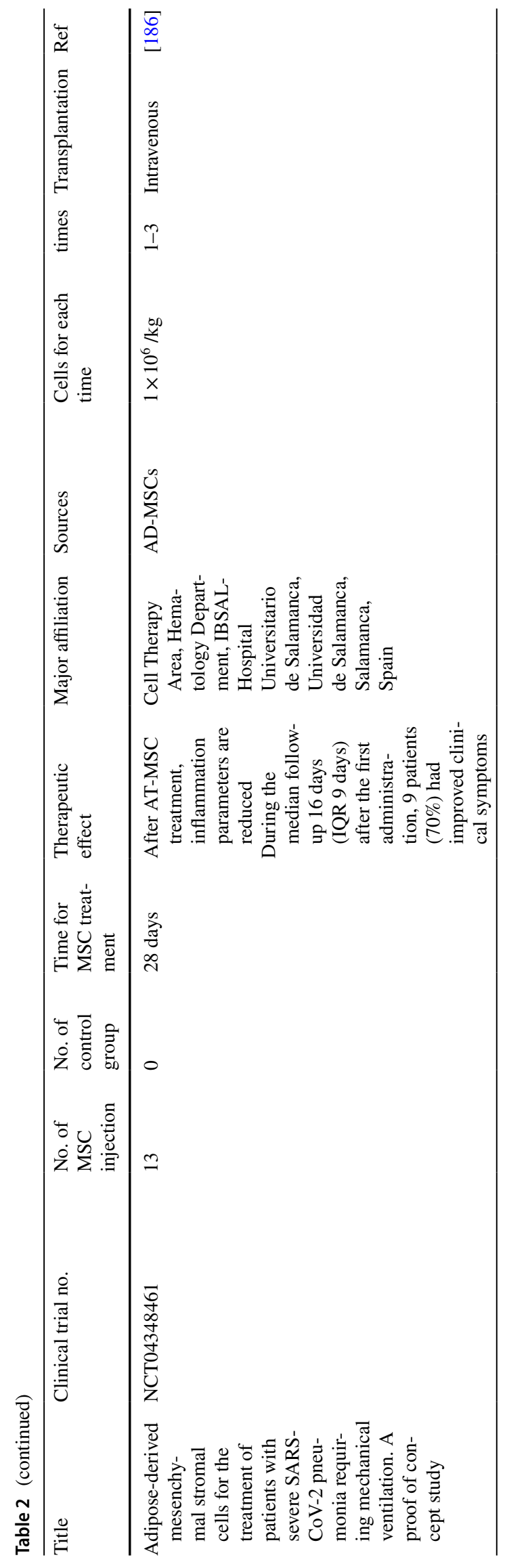

Springer 


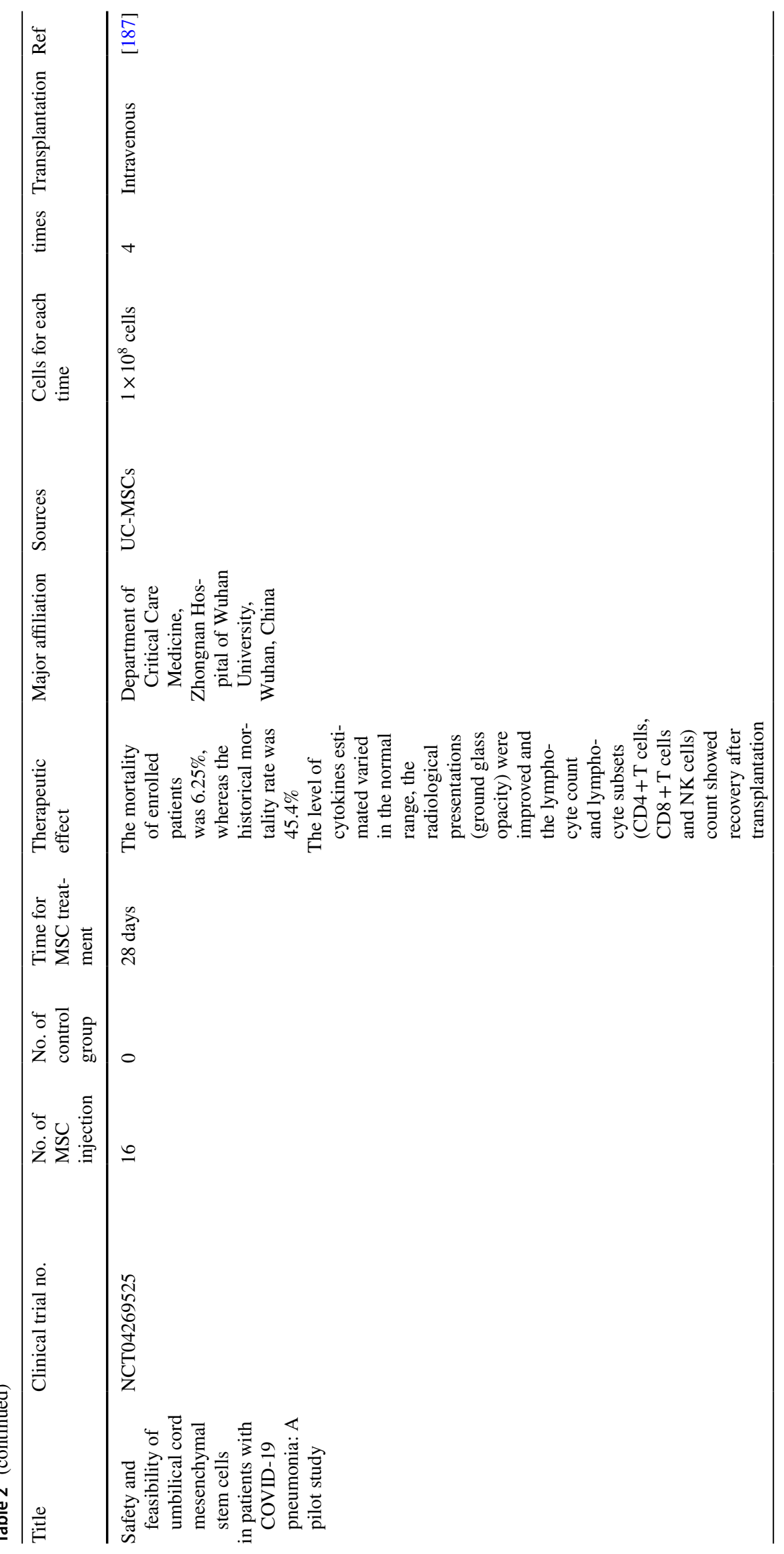




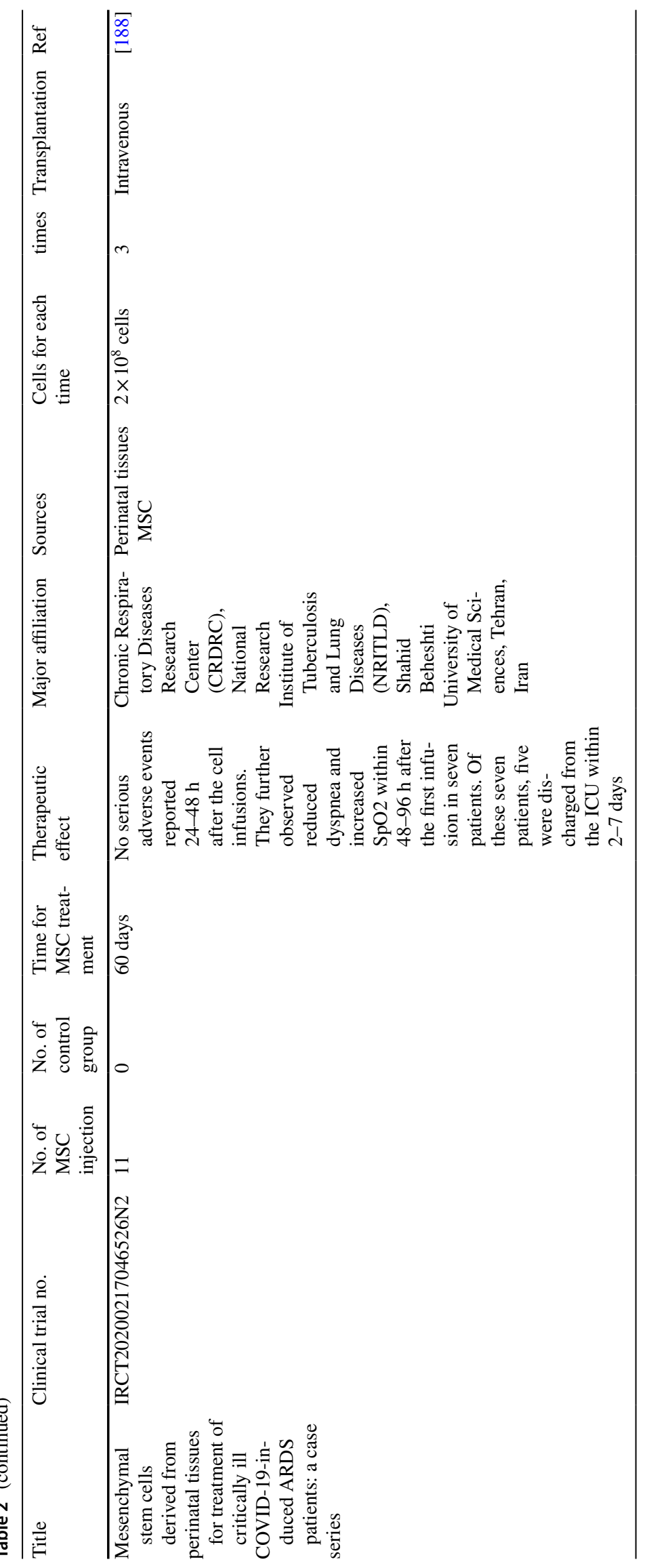




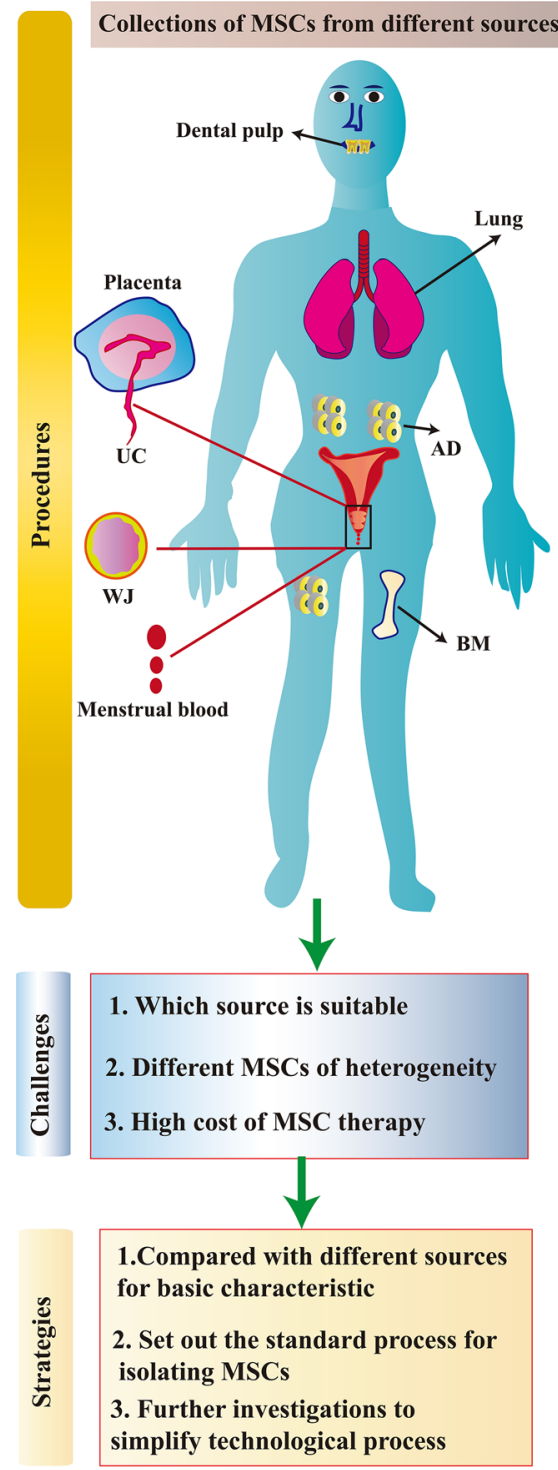

Isolate, identify, multiplication of MSCs
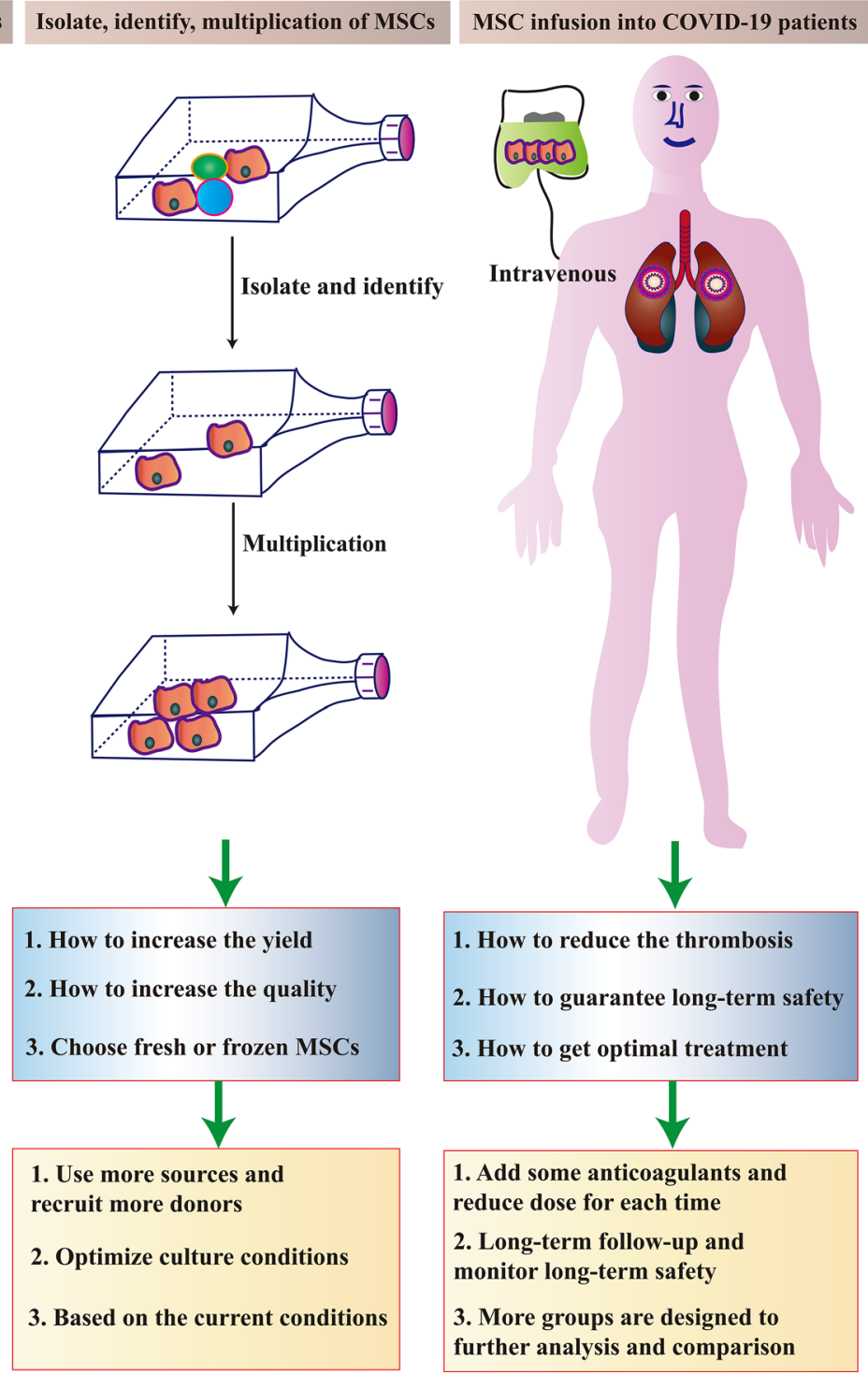

1. How to reduce the thrombosis

2. How to guarantee long-term safety

3. How to get optimal treatment

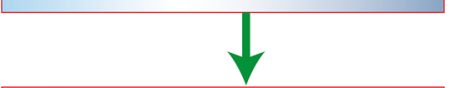

1. Add some anticoagulants and reduce dose for each time

2. Long-term follow-up and monitor long-term safety

3. More groups are designed to further analysis and comparison

Fig. 4 The main challenges and corresponding strategies of MSCbased therapies in clinical applications. There are three steps for the clinical application of MSCs in COVID-19. The first is the collection of MSCs from different sources, then the isolation, identification, and multiplication of MSCs in vitro, and finally, the infusion of MSCs into COVID-19 patients. The challenges faced in each step and their corresponding strategies to overcome these challenges are summarized

permit, fresh MSCs are the first choice, but in emergency situations, frozen MSCs can be utilized. More studies comparing the differences between fresh and frozen MSCs and interpreting existing preclinical data are required to increase our understanding and provide a higher standard of care.

Fourth, regardless of which part of the human body the MSCs were obtained and isolated from, they must be processed in a facility that follows a good manufacturing practice (GMP) and can ensure that the MSCs meet clinical quality standards. Although the effectiveness of MSCs from different sources in the treatment of COVID-19 has been studied, more optimized treatment strategies for evaluating 
and controlling hemocompatibility, optimizing cell infusion, and monitoring the real-time dynamics of cells in the body are essential for the development of safer and more effective MSC therapies [199]. In theory, MSCs can be isolated from most tissues of the human body but are very restricted clinically due to the limited availability of the source tissues, the invasiveness of the procedure, and the general conditions of the donor. It is important to select a suitable cell source, evaluate the difficulties in obtaining samples, and consider the possible adverse effects of the procedure. In summary, although MSCs isolated from different tissues show different common characteristics, their biological functions and markers can differ depending on the tissue source. For many countries, especially developing and underdeveloped countries, the availability of such GMP-compliant cell processing facilities and ensuring the provision of clinical-grade MSCs are major challenges [205]. Even within the same organization, each country may have certain differences and heterogeneity in the production processes with different patient groups using MSCs from different sources.

Then, the high cost of MSC products is an ongoing issue that hinders their large-scale application in the treatment of COVID-19 [206]. Unlike conventional therapeutic methods, MSCs can be collected from both autologous and allogeneic organisms. Standard protocols must be followed when collecting MSCs from the various different sources [207]. Highly specialized technical staff, time costs, technical costs, material costs, testing equipment, quality control costs, cell preservation, and cell transportation costs all require strict maintenance and management by specialized personnel. These personalized procedures make stem cell therapy very expensive. Further investigations into how to effectively control these costs must be conducted in future.

Finally, there is a lack of long-term follow-up data on the tolerance and safety of MSC infusions. Meng et al. conducted a study that included 18 patients with moderate to severe COVID-19, nine of whom received UC-MSC infusion therapy [182]. Based on their results, intravenous infusions of UC-MSCs were found to be safe and well tolerated during the one-month follow-up period. Clinical studies have shown that MSCs have a good therapeutic effect, but some studies have reported that allogeneic AD-MSC infusions are ineffective at improving immune recovery or reducing immune activation and inflammation in patients with an immune response [44]. Our study found that a small number of patients still had adverse events greater than grade 3 at the one-month follow-up period after post-menstrual bloodderived MSC transplantation [181]. Although these adverse events are not considered to be a direct effect of the MSC treatment itself, further verification is still required. Moreover, these clinical studies are currently based on a small sample of participants. Therefore, although MSC transplantation is an effective method for treating COVID-19, particularly critically ill patients, further large-scale clinical studies, potential treatment mechanisms, and long-term safety studies are still required.

\section{Prospective directions for MSC-based COVID-19 therapies}

It is worth noting that intravenous infusions of convalescent plasma can currently be used treat patients with severe COVID-19 and could easily be combined in future with MSC transplants to inhibit cytokine storms, promote lung injury repair, and the recovery of lung function [208]. It is also important to consider that MSCs derived from different tissue sources have phenotypic heterogeneity and exhibit different differentiation possibilities and the release of different biologically active factors [209]. Thus, selecting source MSCs with specific biological properties will help to enable precision therapies in future [210]. For critically ill elderly patients with COVID-19, ready-made sources of allogeneic cells are the best choice. However, for younger patients who are likely to develop COVID-19, autologous sources, such as AD-MSCs, can be used. Furthermore, autologous menstrual blood MSCs may be a good choice for women. Selecting a suitable source for MSCs is vital for the effective treatment of COVID-19. As MSC sources have different quality criteria and researchers have different clinical grades for MSC products, regulations from authorities and clinical guidelines are necessary [211, 212]. To achieve global consensus, some specialists have already proposed therapeutic guidelines for MSC COVID-19 treatments [213, 214].

Understanding the origin of the global COVID-19 pandemic and public health emergency is an ongoing process. It is clear, however, that we must develop a better understanding of how animal viruses can jump species boundaries and effectively infect humans to help prevent future zoonotic events [215]. Some studies have found that bats and pangolins were the intermediate hosts for SARS-CoV-2 [72, 76-79], while other recent studies have found that pets, including cats and dogs, are also susceptible [81, 82]. Therefore, it is possible that the virus infected humans indirectly via transmission from wild animals to domestic pets. However, these are conjectures. The true origins and the process of how viruses infect specific animals and subsequently pass to humans should be explored from all angles in future.

Due to a lack of studies comparing the efficacy of MSCs and MSC-derived EVs, it is currently unclear which treatment should be used. Current reports of MSC-derived EVs for the treatment of COVID-19 are continuous and effective [216-220]. However, since some studies have verified the importance of direct cell contact to the success of treatment and considering the urgency of treatment, it makes sense to use MSCs directly. Nevertheless, both therapies 
are likely to be accepted, as evidenced by clinical studies with COVID-19 patients. Based on this evidence, we hypothesize that MSCs in the form of a freeze-dried powder, administered by intravenous transplant (or inhalation, etc.), may be a suitable method for treating COVID-19 in future, particularly critically ill patients. Further analysis of MSCs and MSC-EVs will help to further understand the differences and respective advantages of these treatment methods.

\section{Conclusion}

Clinical studies have indicated that MSCs from various sources could be utilized in future treatment methods for patients with COVID-19 (especially critically ill patients). MSCs have already shown potential as adjuvant treatments for COVID-19 in preliminary studies. However, MSC treatments for COVID-19 are currently lacking important longterm safety information and data from large-scale controlled trials, which is required to make conclusive judgments. With the continuous development of new technologies, we have come to understand that combined treatments can be more effective and advantageous, and that we should keep this in mind when considering treatments for COVID-19 in future. Thus, MSC-based treatments combined with other treatment methods could play a powerful role in developing effective strategies to combat COVID-19.

Acknowledgements The authors thank Prof. Hongcui Cao and Prof. Xiaowei Xu from The First Affiliated Hospital, College of Medicine, Zhejiang University for technical help of this manuscript. Additionally, we would like to thank Editage (http://www.editage.cn) for English language editing.

Author contributions LC wrote the manuscript; JQ, FSK, QZ, LF, YF, YL collected the references and modified the manuscript; CX designed the manuscript and approved the final manuscript for publication.

Funding This work was supported by the National Natural Science Foundation of China (81900563 and 81802278), the Zhejiang Key Research and Development Program (2020C03125 and 2020C04016), the Independent Task of State Key Laboratory for Diagnosis and Treatment of Infectious Diseases, and the National Key R\&D Program of China, Key Technologies Research and Development Program (2017YFA0105701).

Data availability Please contact the corresponding author for data requests.

\section{Declarations}

Conflict of interest The authors declare that they have no competing interests.

Ethics approval and consent to participate Not applicable.

\section{References}

1. Huang C, Wang Y, Li X, Ren L, Zhao J, Hu Y, Zhang L, Fan $\mathrm{G}, \mathrm{Xu} \mathrm{J}, \mathrm{Gu} X$ et al (2020) Clinical features of patients infected with 2019 novel coronavirus in Wuhan, China. Lancet (London, England) 395(10223):497-506

2. Guan WJ, Ni ZY, Hu Y, Liang WH, Ou CQ, He JX, Liu L, Shan H, Lei CL, Hui DSC et al (2020) Clinical characteristics of coronavirus disease 2019 in China. N Engl J Med 382(18):1708-1720

3. Hu B, Guo H, Zhou P, Shi ZL (2021) Characteristics of SARSCoV-2 and COVID-19. Nat Rev Microbiol 19(3):141-154

4. Bates TA, Weinstein JB, Farley S, Leier HC, Messer WB, Tafesse FG (2021) Cross-reactivity of SARS-CoV structural protein antibodies against SARS-CoV-2. Cell Rep 34(7):108737

5. Lal A, Erondu NA, Heymann DL, Gitahi G, Yates R (2021) Fragmented health systems in COVID-19: rectifying the misalignment between global health security and universal health coverage. Lancet (London, England) 397(10268):61-67

6. Tang D, Comish P, Kang R (2020) The hallmarks of COVID-19 disease. PLoS Pathog 16(5):e1008536

7. Cucinotta D, Vanelli M (2020) WHO declares COVID-19 a pandemic. Acta Biomed 91(1):157-160

8. Wolfel R, Corman VM, Guggemos W, Seilmaier M, Zange S, Muller MA, Niemeyer D, Jones TC, Vollmar P, Rothe C et al (2020) Virological assessment of hospitalized patients with COVID-2019. Nature 581(7809):465-469

9. Moll G, Drzeniek N, Kamhieh-Milz J, Geissler S, Volk HD, Reinke P (2020) MSC Therapies for COVID-19: importance of patient coagulopathy, thromboprophylaxis, cell product quality and mode of delivery for treatment safety and efficacy. Front Immunol 11:1091

10. Kanamori H, Weber DJ, Rutala WA (2021) Role of the healthcare surface environment in severe acute respiratory syndrome coronavirus 2 (SARS-CoV-2) transmission and potential control measures. Clin Infect Dis 72(11):2052-2061

11. Wynants L, Van Calster B, Collins GS, Riley RD, Heinze G, Schuit E, Bonten MMJ, Dahly DL, Damen JAA, Debray TPA et al (2020) Prediction models for diagnosis and prognosis of covid-19 infection: systematic review and critical appraisal. BMJ 369:m1328

12. Chung JY, Thone MN, Kwon YJ (2021) COVID-19 vaccines: the status and perspectives in delivery points of view. Adv Drug Deliv Rev 170:1-25

13. Gebre MS, Brito LA, Tostanoski LH, Edwards DK, Carfi A, Barouch DH (2021) Novel approaches for vaccine development. Cell 184(6):1589-1603

14. Koff WC, Schenkelberg T, Williams T, Baric RS, McDermott A, Cameron CM, Cameron MJ, Friemann MB, Neumann G, Kawaoka Y et al (2021) Development and deployment of COVID-19 vaccines for those most vulnerable. Sci Transl Med 13(579):eabd 1525

15. Hacisuleyman E, Hale C, Saito Y, Blachere NE, Bergh M, Conlon EG, Schaefer-Babajew DJ, DaSilva J, Muecksch F, Gaebler C et al (2021) Vaccine breakthrough infections with SARS-CoV-2 variants. N Engl J Med 384:2212-2218

16. Wang Z, Schmidt F, Weisblum Y, Muecksch F, Barnes CO, Finkin S, Schaefer-Babajew D, Cipolla M, Gaebler C, Lieberman JA et al (2021) mRNA vaccine-elicited antibodies to SARSCoV-2 and circulating variants. Nature 592(7855):616-622

17. Karpinski TM, Ozarowski M, Seremak-Mrozikiewicz A, Wolski H, Wlodkowic D (2021) The 2020 race towards SARS-CoV-2 specific vaccines. Theranostics 11(4):1690-1702

18. Zhu F-C, Li Y-H, Guan X-H, Hou L-H, Wang W-J, Li J-X, Wu S-P, Wang B-S, Wang Z, Wang L et al (2020) Safety, tolerability, and immunogenicity of a recombinant adenovirus type- 5 
vectored COVID-19 vaccine: a dose-escalation, open-label, non-randomised, first-in-human trial. Lancet (London, England) 395(10240): 1845-1854

19. Folegatti PM, Ewer KJ, Aley PK, Angus B, Becker S, BelijRammerstorfer S, Bellamy D, Bibi S, Bittaye M, Clutterbuck EA et al (2020) Safety and immunogenicity of the ChAdOx1 nCoV-19 vaccine against SARS-CoV-2: a preliminary report of a phase 1/2, single-blind, randomised controlled trial. Lancet (London, England) 396(10249):467-478

20. Mulligan MJ, Lyke KE, Kitchin N, Absalon J, Gurtman A, Lockhart S, Neuzil K, Raabe V, Bailey R, Swanson KA et al (2020) Phase I/II study of COVID-19 RNA vaccine BNT162b1 in adults. Nature 586(7830):589-593

21. Polack FP, Thomas SJ, Kitchin N, Absalon J, Gurtman A, Lockhart S, Perez JL, Perez Marc G, Moreira ED, Zerbini C et al (2020) Safety and efficacy of the BNT162b2 mRNA Covid-19 vaccine. N Engl J Med 383(27):2603-2615

22. Haas EJ, Angulo FJ, McLaughlin JM, Anis E, Singer SR, Khan F, Brooks N, Smaja M, Mircus G, Pan K et al (2021) Impact and effectiveness of mRNA BNT162b2 vaccine against SARSCoV-2 infections and COVID-19 cases, hospitalisations, and deaths following a nationwide vaccination campaign in Israel: an observational study using national surveillance data. Lancet (London, England) 397(10287):1819-1829

23. Voysey M, Clemens SAC, Madhi SA, Weckx LY, Folegatti PM, Aley PK, Angus B, Baillie VL, Barnabas SL, Bhorat QE et al (2021) Safety and efficacy of the ChAdOx $1 \mathrm{nCoV}-19$ vaccine (AZD1222) against SARS-CoV-2: an interim analysis of four randomised controlled trials in Brazil, South Africa, and the UK. Lancet (London, England) 397(10269):99-111

24. Ramasamy MN, Minassian AM, Ewer KJ, Flaxman AL, Folegatti PM, Owens DR, Voysey M, Aley PK, Angus B, Babbage G et al (2021) Safety and immunogenicity of ChAdOx $1 \mathrm{nCoV}-19$ vaccine administered in a prime-boost regimen in young and old adults (COV002): a single-blind, randomised, controlled, phase 2/3 trial. Lancet (London, England) 396(10267):1979-1993

25. Jackson LA, Anderson EJ, Rouphael NG, Roberts PC, Makhene M, Coler RN, McCullough MP, Chappell JD, Denison MR, Stevens $L J$ et al (2020) An mRNA vaccine against SARS-CoV-2 preliminary report. N Engl J Med 383(20):1920-1931

26. Baden LR, El Sahly HM, Essink B, Kotloff K, Frey S, Novak R, Diemert D, Spector SA, Rouphael N, Creech CB et al (2021) Efficacy and safety of the mRNA-1273 SARS-CoV-2 vaccine. N Engl J Med 384(5):403-416

27. Keech C, Albert G, Cho I, Robertson A, Reed P, Neal S, Plested JS, Zhu M, Cloney-Clark S, Zhou H et al (2020) Phase 1-2 trial of a SARS-CoV-2 recombinant spike protein nanoparticle vaccine. N Engl J Med 383(24):2320-2332

28. Shinde V, Bhikha S, Hoosain Z, Archary M, Bhorat Q, Fairlie L, Lalloo U, Masilela MSL, Moodley D, Hanley S et al (2021) Efficacy of NVX-CoV2373 Covid-19 vaccine against the B.1.351 variant. N Engl J Med 384(20):1899-1909

29. Logunov DY, Dolzhikova IV, Shcheblyakov DV, Tukhvatulin AI, Zubkova OV, Dzharullaeva AS, Kovyrshina AV, Lubenets NL, Grousova DM, Erokhova AS et al (2021) Safety and efficacy of an rAd26 and rAd5 vector-based heterologous prime-boost COVID-19 vaccine: an interim analysis of a randomised controlled phase 3 trial in Russia. Lancet 397(10275):671-681

30. Zhu F-C, Guan X-H, Li Y-H, Huang J-Y, Jiang T, Hou L-H, Li J-X, Yang B-F, Wang L, Wang W-J et al (2020) Immunogenicity and safety of a recombinant adenovirus type-5-vectored COVID-19 vaccine in healthy adults aged 18 years or older: a randomised, double-blind, placebo-controlled, phase 2 trial. Lancet (London, England) 396(10249):479-488

31. Xia S, Zhang Y, Wang Y, Wang H, Yang Y, Gao GF, Tan W, Wu G, Xu M, Lou Z et al (2021) Safety and immunogenicity of an inactivated SARS-CoV-2 vaccine, BBIBP-CorV: a randomised, double-blind, placebo-controlled, phase $1 / 2$ trial. Lancet Infect Dis 21(1):39-51

32. Wang H, Zhang Y, Huang B, Deng W, Quan Y, Wang W, Xu W, Zhao Y, Li N, Zhang J et al (2020) Development of an inactivated vaccine candidate, BBIBP-CorV, with potent protection against SARS-CoV-2. Cell 182(3):713 e719-721 e719

33. Zhang Y, Zeng G, Pan H, Li C, Hu Y, Chu K, Han W, Chen $Z$, Tang R, Yin W et al (2021) Safety, tolerability, and immunogenicity of an inactivated SARS-CoV-2 vaccine in healthy adults aged 18-59 years: a randomised, double-blind, placebo-controlled, phase 1/2 clinical trial. Lancet Infect Dis 21(2):181-192

34. Wu Z, Hu Y, Xu M, Chen Z, Yang W, Jiang Z, Li M, Jin H, Cui $\mathrm{G}$, Chen P et al (2021) Safety, tolerability, and immunogenicity of an inactivated SARS-CoV-2 vaccine (CoronaVac) in healthy adults aged 60 years and older: a randomised, double-blind, placebo-controlled, phase 1/2 clinical trial. Lancet Infect Dis 21:803-812

35. Ella R, Vadrevu KM, Jogdand H, Prasad S, Reddy S, Sarangi V, Ganneru B, Sapkal G, Yadav P, Abraham P et al (2021) Safety and immunogenicity of an inactivated SARS-CoV-2 vaccine, BBV152: a double-blind, randomised, phase 1 trial. Lancet Infect Dis 21(5):637-646

36. Ella R, Reddy S, Jogdand H, Sarangi V, Ganneru B, Prasad S, Das D, Raju D, Praturi U, Sapkal G et al (2021) Safety and immunogenicity of an inactivated SARS-CoV-2 vaccine, BBV152: interim results from a double-blind, randomised, multicentre, phase 2 trial, and 3-month follow-up of a double-blind, randomised phase 1 trial. Lancet Infect Dis 21(7):950-961

37. Castells MC, Phillips EJ (2021) Maintaining safety with SARSCoV-2 vaccines. N Engl J Med 384(7):643-649

38. Lazarus JV, Ratzan SC, Palayew A, Gostin LO, Larson HJ, Rabin K, Kimball S, El-Mohandes A (2021) A global survey of potential acceptance of a COVID-19 vaccine. Nat Med 27(2):225-228

39. Group RC, Horby P, Lim WS, Emberson JR, Mafham M, Bell JL, Linsell L, Staplin N, Brightling C, Ustianowski A et al (2021) Dexamethasone in hospitalized patients with Covid-19. N Engl J Med 384(8):693-704

40. Wang Y, Zhang D, Du G, Du R, Zhao J, Jin Y, Fu S, Gao L, Cheng Z, Lu Q et al (2020) Remdesivir in adults with severe COVID-19: a randomised, double-blind, placebo-controlled, multicentre trial. Lancet (London, England) 395(10236):1569-1578

41. Cai Q, Yang M, Liu D, Chen J, Shu D, Xia J, Liao X, Gu Y, Cai Q, Yang Y et al (2020) Experimental treatment with favipiravir for COVID-19: an open-label control study. Engineering (Beijing) 6(10):1192-1198

42. Galipeau J, Sensebe L (2018) Mesenchymal stromal cells: clinical challenges and therapeutic opportunities. Cell Stem Cell 22(6):824-833

43. Han Y, Li X, Zhang Y, Han Y, Chang F, Ding J (2019) Mesenchymal stem cells for regenerative medicine. Cells 8(8):886

44. Trujillo-Rodriguez M, Viciana P, Rivas-Jeremias I, Alvarez-Rios AI, Ruiz-Garcia A, Espinosa-Ibanez O, Arias-Santiago S, Martinez-Atienza J, Mata R, Fernandez-Lopez O et al (2021) Mesenchymal stromal cells in human immunodeficiency virus-infected patients with discordant immune response: early results of a phase I/II clinical trial. Stem Cells Transl Med 10(4):534-541

45. Weiss ARR, Dahlke MH (2019) Immunomodulation by mesenchymal stem cells (MSCs): mechanisms of action of living, apoptotic, and dead MSCs. Front Immunol 10:1191

46. Samsonraj RM, Raghunath M, Nurcombe V, Hui JH, van Wijnen AJ, Cool SM (2017) Concise review: multifaceted characterization of human mesenchymal stem cells for use in regenerative medicine. Stem Cells Transl Med 6(12):2173-2185 
47. Andrzejewska A, Lukomska B, Janowski M (2019) Concise review: mesenchymal stem cells: from roots to boost. Stem Cells 37(7):855-864

48. Chen L, Qu J, Cheng T, Chen X, Xiang C (2019) Menstrual blood-derived stem cells: toward therapeutic mechanisms, novel strategies, and future perspectives in the treatment of diseases. Stem Cell Res Ther 10(1):406

49. Mushahary D, Spittler A, Kasper C, Weber V, Charwat V (2018) Isolation, cultivation, and characterization of human mesenchymal stem cells. Cytom A 93(1):19-31

50. Hass R, Kasper C, Bohm S, Jacobs R (2011) Different populations and sources of human mesenchymal stem cells (MSC): a comparison of adult and neonatal tissue-derived MSC. Cell Commun Signal 9:12

51. Bianco P (2014) "Mesenchymal" stem cells. Annu Rev Cell Dev Biol 30:677-704

52. Uccelli A, Moretta L, Pistoia V (2008) Mesenchymal stem cells in health and disease. Nat Rev Immunol 8(9):726-736

53. Yin JQ, Zhu J, Ankrum JA (2019) Manufacturing of primed mesenchymal stromal cells for therapy. Nat Biomed Eng 3(2):90-104

54. Le Blanc K, Davies LC (2018) MSCs—cells with many sides. Cytotherapy 20(3):273-278

55. Fan XL, Zhang Y, Li X, Fu QL (2020) Mechanisms underlying the protective effects of mesenchymal stem cell-based therapy. Cell Mol Life Sci 77(14):2771-2794

56. Le Blanc K, Mougiakakos D (2012) Multipotent mesenchymal stromal cells and the innate immune system. Nat Rev Immunol 12(5):383-396

57. Song N, Scholtemeijer M, Shah K (2020) Mesenchymal stem cell immunomodulation: mechanisms and therapeutic potential. Trends Pharmacol Sci 41(9):653-664

58. Wu X, Jiang J, Gu Z, Zhang J, Chen Y, Liu X (2020) Mesenchymal stromal cell therapies: immunomodulatory properties and clinical progress. Stem Cell Res Ther 11(1):345

59. Kabat M, Bobkov I, Kumar S, Grumet M (2020) Trends in mesenchymal stem cell clinical trials 2004-2018: is efficacy optimal in a narrow dose range? Stem Cells Transl Med 9(1):17-27

60. Mastrolia I, Foppiani EM, Murgia A, Candini O, Samarelli AV, Grisendi G, Veronesi E, Horwitz EM, Dominici M (2019) Challenges in clinical development of mesenchymal stromal/stem cells: concise review. Stem Cells Transl Med 8(11):1135-1148

61. Wilson JG, Liu KD, Zhuo H, Caballero L, McMillan M, Fang X, Cosgrove K, Vojnik R, Calfee CS, Lee J-W et al (2015) Mesenchymal stem (stromal) cells for treatment of ARDS: a phase 1 clinical trial. Lancet Respir Med 3(1):24-32

62. Chen J, Hu C, Chen L, Tang L, Zhu Y, Xu X, Chen L, Gao H, Lu X, Yu L et al (2020) Clinical study of mesenchymal stem cell treating acute respiratory distress syndrome induced by epidemic Influenza A (H7N9) infection, a hint for COVID-19 treatment. Engineering (Beijing) 6(10):1153-1161

63. Walls AC, Park YJ, Tortorici MA, Wall A, McGuire AT, Veesler D (2020) Structure, function, and antigenicity of the SARSCoV-2 spike glycoprotein. Cell 181(2):281 e286-292 e286

64. Yang J, Petitjean SJL, Koehler M, Zhang Q, Dumitru AC, Chen W, Derclaye S, Vincent SP, Soumillion P, Alsteens D (2020) Molecular interaction and inhibition of SARS-CoV-2 binding to the ACE2 receptor. Nat Commun 11(1):4541

65. Schafer R, Spohn G, Bechtel M, Bojkova D, Baer PC, Kuci S, Seifried E, Ciesek S, Cinatl J (2021) Human mesenchymal stromal cells are resistant to SARS-CoV-2 infection under steadystate, inflammatory conditions and in the presence of SARSCoV-2-infected cells. Stem Cell Rep 16(3):419-427

66. Avanzini MA, Mura M, Percivalle E, Bastaroli F, Croce S, Valsecchi C, Lenta E, Nykjaer G, Cassaniti I, Bagnarino J et al (2021) Human mesenchymal stromal cells do not express ACE2 and
TMPRSS2 and are not permissive to SARS-CoV-2 infection. Stem Cells Transl Med 10(4):636-642

67. Ganesh B, Rajakumar T, Malathi M, Manikandan N, Nagaraj J, Santhakumar A, Elangovan A, Malik YS (2021) Epidemiology and pathobiology of SARS-CoV-2 (COVID-19) in comparison with SARS, MERS: An updated overview of current knowledge and future perspectives. Clin Epidemiol Glob Health 10:100694

68. Park BK, Kim J, Park S, Kim D, Kim M, Baek K, Bae JY, Park MS, Kim WK, Lee Y et al (2021) MERS-CoV and SARS-CoV-2 replication can be inhibited by targeting the interaction between the viral spike protein and the nucleocapsid protein. Theranostics 11(8):3853-3867

69. Yan Y, Chang L, Wang L (2020) Laboratory testing of SARSCoV, MERS-CoV, and SARS-CoV-2 (2019-nCoV): current status, challenges, and countermeasures. Rev Med Virol 30(3): 2106

70. V'Kovski P, Kratzel A, Steiner S, Stalder H, Thiel V (2021) Coronavirus biology and replication: implications for SARSCoV-2. Nat Rev Microbiol 19(3):155-170

71. Wang F, Huang S, Gao R, Zhou Y, Lai C, Li Z, Xian W, Qian X, Li Z, Huang Y et al (2020) Initial whole-genome sequencing and analysis of the host genetic contribution to COVID-19 severity and susceptibility. Cell Discov 6(1):83

72. Lu R, Zhao X, Li J, Niu P, Yang B, Wu H, Wang W, Song H, Huang B, Zhu N et al (2020) Genomic characterisation and epidemiology of 2019 novel coronavirus: implications for virus origins and receptor binding. Lancet (London, England) 395(10224):565-574

73. Li W, Shi Z, Yu M, Ren W, Smith C, Epstein JH, Wang H, Crameri G, Hu Z, Zhang H et al (2005) Bats are natural reservoirs of SARS-like coronaviruses. Science (New York, NY) 310(5748):676-679

74. Mohd HA, Al-Tawfiq JA, Memish ZA (2016) Middle East Respiratory Syndrome Coronavirus (MERS-CoV) origin and animal reservoir. Virol J 13:87

75. Li Q, Guan X, Wu P, Wang X, Zhou L, Tong Y, Ren R, Leung KSM, Lau EHY, Wong JY et al (2020) Early transmission dynamics in Wuhan, China, of novel coronavirus-infected pneumonia. N Engl J Med 382(13):1199-1207

76. Zhou P, Yang XL, Wang XG, Hu B, Zhang L, Zhang W, Si HR, Zhu Y, Li B, Huang CL et al (2020) A pneumonia outbreak associated with a new coronavirus of probable bat origin. Nature 579(7798):270-273

77. Conceicao C, Thakur N, Human S, Kelly JT, Logan L, Bialy D, Bhat S, Stevenson-Leggett $P$, Zagrajek AK, Hollinghurst $P$ et al (2020) The SARS-CoV-2 Spike protein has a broad tropism for mammalian ACE2 proteins. PLoS Biol 18(12):e3001016

78. Lam TT, Jia N, Zhang YW, Shum MH, Jiang JF, Zhu HC, Tong YG, Shi YX, Ni XB, Liao YS et al (2020) Identifying SARSCoV-2-related coronaviruses in Malayan pangolins. Nature 583(7815):282-285

79. Xiao K, Zhai J, Feng Y, Zhou N, Zhang X, Zou JJ, Li N, Guo Y, Li X, Shen X et al (2020) Isolation of SARS-CoV-2-related coronavirus from Malayan pangolins. Nature 583(7815):286-289

80. Oude Munnink BB, Sikkema RS, Nieuwenhuijse DF, Molenaar RJ, Munger E, Molenkamp R, van der Spek A, Tolsma P, Rietveld A, Brouwer $\mathrm{M}$ et al (2021) Transmission of SARS-CoV-2 on mink farms between humans and mink and back to humans. Science (New York, NY) 371(6525):172-177

81. Patterson EI, Elia G, Grassi A, Giordano A, Desario C, Medardo M, Smith SL, Anderson ER, Prince T, Patterson GT et al (2020) Evidence of exposure to SARS-CoV-2 in cats and dogs from households in Italy. Nat Commun 11(1):6231

82. Segales J, Puig M, Rodon J, Avila-Nieto C, Carrillo J, Cantero G, Terron MT, Cruz S, Parera M, Noguera-Julian M et al (2020) Detection of SARS-CoV-2 in a cat owned by a 
COVID-19-affected patient in Spain. Proc Natl Acad Sci USA 117(40):24790-24793

83. Boutin S, Hildebrand D, Boulant S, Kreuter M, Ruter J, Pallerla SR, Velavan TP, Nurjadi D (2021) Host factors facilitating SARS-CoV-2 virus infection and replication in the lungs. Cell Mol Life Sci 78(16):5953-5976

84. Clausen TM, Sandoval DR, Spliid CB, Pihl J, Perrett HR, Painter CD, Narayanan A, Majowicz SA, Kwong EM, McVicar RN et al (2020) SARS-CoV-2 infection depends on cellular heparan sulfate and ACE2. Cell 183(4):1043 e1015-1057 e1015

85. Lukassen S, Chua RL, Trefzer T, Kahn NC, Schneider MA, Muley T, Winter H, Meister M, Veith C, Boots AW et al (2020) SARS-CoV-2 receptor ACE2 and TMPRSS2 are primarily expressed in bronchial transient secretory cells. EMBO J 39(10):e105114

86. Hoffmann M, Kleine-Weber H, Schroeder S, Kruger N, Herrler T, Erichsen S, Schiergens TS, Herrler G, Wu NH, Nitsche A et al (2020) SARS-CoV-2 cell entry depends on ACE2 and TMPRSS 2 and is blocked by a clinically proven protease inhibitor. Cell 181(2):271 e278-280 e278

87. Mercurio I, Tragni V, Busto F, De Grassi A, Pierri CL (2021) Protein structure analysis of the interactions between SARSCoV-2 spike protein and the human ACE2 receptor: from conformational changes to novel neutralizing antibodies. Cell Mol Life Sci 78(4):1501-1522

88. Zindel J, Kubes P (2020) DAMPs, PAMPs, and LAMPs in immunity and sterile inflammation. Annu Rev Pathol 15:493-518

89. Arango Duque G, Descoteaux A (2014) Macrophage cytokines: involvement in immunity and infectious diseases. Front Immunol $5: 491$

90. Kumar V, Doshi KU, Khan WH, Rathore AS (2021) COVID-19 pandemic: mechanism, diagnosis, and treatment. J Chem Technol Biotechnol 96(2):299-308

91. Long QX, Tang XJ, Shi QL, Li Q, Deng HJ, Yuan J, Hu JL, Xu W, Zhang Y, Lv FJ et al (2020) Clinical and immunological assessment of asymptomatic SARS-CoV-2 infections. Nat Med 26(8):1200-1204

92. Pairo-Castineira E, Clohisey S, Klaric L, Bretherick AD, Rawlik K, Pasko D, Walker S, Parkinson N, Fourman MH, Russell CD et al (2021) Genetic mechanisms of critical illness in COVID-19. Nature 591(7848):92-98

93. Chen N, Zhou M, Dong X, Qu J, Gong F, Han Y, Qiu Y, Wang J, Liu Y, Wei Y et al (2020) Epidemiological and clinical characteristics of 99 cases of 2019 novel coronavirus pneumonia in Wuhan, China: a descriptive study. Lancet (London, England) 395(10223):507-513

94. Lauer SA, Grantz KH, Bi Q, Jones FK, Zheng Q, Meredith HR, Azman AS, Reich NG, Lessler J (2020) The incubation period of coronavirus disease 2019 (COVID-19) from publicly reported confirmed cases: estimation and application. Ann Intern Med 172(9):577-582

95. Fox SE, Akmatbekov A, Harbert JL, Li G, Quincy Brown J, Vander Heide RS (2020) Pulmonary and cardiac pathology in African American patients with COVID-19: an autopsy series from New Orleans. Lancet Respir Med 8(7):681-686

96. Xu Z, Shi L, Wang Y, Zhang J, Huang L, Zhang C, Liu S, Zhao $\mathrm{P}$, Liu H, Zhu L et al (2020) Pathological findings of COVID19 associated with acute respiratory distress syndrome. Lancet Respir Med 8(4):420-422

97. Hariri LP, North CM, Shih AR, Israel RA, Maley JH, Villalba JA, Vinarsky V, Rubin J, Okin DA, Sclafani A et al (2021) Lung histopathology in coronavirus disease 2019 as compared with severe acute respiratory syndrome and H1N1 influenza: a systematic review. Chest 159(1):73-84

98. Xu X-W, Wu X-X, Jiang X-G, Xu K-J, Ying L-J, Ma C-L, Li S-B, Wang H-Y, Zhang S, Gao H-N et al (2020) Clinical findings in a group of patients infected with the 2019 novel coronavirus (SARS-Cov-2) outside of Wuhan, China: retrospective case series. BMJ 368:m606

99. Xu M, Wang D, Wang H, Zhang X, Liang T, Dai J, Li M, Zhang J, Zhang K, Xu D et al (2020) COVID-19 diagnostic testing: technology perspective. Clin Transl Med 10(4):e158

100. Wiersinga WJ, Rhodes A, Cheng AC, Peacock SJ, Prescott HC (2020) Pathophysiology, transmission, diagnosis, and treatment of coronavirus disease 2019 (COVID-19): a review. JAMA 324(8):782-793

101. Li Y, Hou G, Zhou H, Wang Y, Tun HM, Zhu A, Zhao J, Xiao F, Lin S, Liu D et al (2021) Multi-platform omics analysis reveals molecular signature for COVID-19 pathogenesis, prognosis and drug target discovery. Signal Transduct Target Ther 6(1):155

102. Wu P, Chen D, Ding W, Wu P, Hou H, Bai Y, Zhou Y, Li K, Xiang S, Liu P et al (2021) The trans-omics landscape of COVID-19. Nat Commun 12(1):4543

103. Yang X, Cai S, Luo Y, Zhu F, Hu M, Zhao Y, Zheng R, Li X, Hu B, Peng Z (2020) Extracorporeal membrane oxygenation for coronavirus disease 2019-induced acute respiratory distress syndrome: a multicenter descriptive study. Crit Care Med 48(9):1289-1295

104. Joyner MJ, Wright RS, Fairweather D, Senefeld JW, Bruno KA, Klassen SA, Carter RE, Klompas AM, Wiggins CC, Shepherd JR et al (2020) Early safety indicators of COVID-19 convalescent plasma in 5000 patients. J Clin Investig 130(9):4791-4797

105. Florindo HF, Kleiner R, Vaskovich-Koubi D, Acurcio RC, Carreira B, Yeini E, Tiram G, Liubomirski Y, Satchi-Fainaro R (2020) Immune-mediated approaches against COVID-19. Nat Nanotechnol 15(8):630-645

106. Ni L, Chen L, Huang X, Han C, Xu J, Zhang H, Luan X, Zhao Y, Xu J, Yuan W et al (2020) Combating COVID-19 with integrated traditional Chinese and Western medicine in China. Acta Pharm Sin B 10(7):1149-1162

107. Indari O, Jakhmola S, Manivannan E, Jha HC (2021) An update on antiviral therapy against SARS-CoV-2: how far have we come? Front Pharmacol 12:632677

108. Esquivel D, Mishra R, Soni P, Seetharaman R, Mahmood A, Srivastava A (2021) Stem cells therapy as a possible therapeutic option in treating COVID-19 patients. Stem Cell Rev Rep 17(1):144-152

109. Bharat A, Querrey M, Markov NS, Kim S, Kurihara C, GarzaCastillon R, Manerikar A, Shilatifard A, Tomic R, Politanska $Y$ et al (2020) Lung transplantation for patients with severe COVID-19. Sci Transl Med 12(574):eabe4282

110. Zhou W, Liu Y, Tian D, Wang C, Wang S, Cheng J, Hu M, Fang M, Gao Y (2020) Potential benefits of precise corticosteroids therapy for severe 2019-nCoV pneumonia. Signal Transduct Target Ther 5(1): 18

111. Sharma A, Ahmad Farouk I, Lal SK (2021) COVID-19: a review on the novel coronavirus disease evolution, transmission, detection, control and prevention. Viruses 13(2):202

112. Sun J, He WT, Wang L, Lai A, Ji X, Zhai X, Li G, Suchard MA, Tian J, Zhou J et al (2020) COVID-19: epidemiology, evolution, and cross-disciplinary perspectives. Trends Mol Med 26(5):483-495

113. Pittenger MF, Discher DE, Peault BM, Phinney DG, Hare JM, Caplan AI (2019) Mesenchymal stem cell perspective: cell biology to clinical progress. NPJ Regen Med 4:22

114. Behnke J, Kremer S, Shahzad T, Chao CM, Bottcher-Friebertshauser E, Morty RE, Bellusci S, Ehrhardt H (2020) MSC based therapies-new perspectives for the injured lung. J Clin Med 9(3):682

115. Harrell CR, Sadikot R, Pascual J, Fellabaum C, Jankovic MG, Jovicic N, Djonov V, Arsenijevic N, Volarevic V (2019) Mesenchymal stem cell-based therapy of inflammatory lung diseases: 
current understanding and future perspectives. Stem Cells Int 2019:4236973

116. Matthay MA, Thompson BT, Read EJ, McKenna DH Jr, Liu KD, Calfee CS, Lee JW (2010) Therapeutic potential of mesenchymal stem cells for severe acute lung injury. Chest 138(4):965-972

117. Loy H, Kuok DIT, Hui KPY, Choi MHL, Yuen W, Nicholls JM, Peiris JSM, Chan MCW (2019) Therapeutic implications of human umbilical cord mesenchymal stromal cells in attenuating influenza A (H5N1) virus-associated acute lung injury. J Infect Dis 219(2):186-196

118. Zhu J, Feng B, Xu Y, Chen W, Sheng X, Feng X, Shi X, Liu J, Pan Q, Yu J et al (2020) Mesenchymal stem cells alleviate LPS-induced acute lung injury by inhibiting the proinflammatory function of Ly6C(+) CD8(+) T cells. Cell Death Dis 11(10):829

119. Toonkel RL, Hare JM, Matthay MA, Glassberg MK (2013) Mesenchymal stem cells and idiopathic pulmonary fibrosis. Potential for clinical testing. Am J Respir Crit Care Med 188(2):133-140

120. Tzouvelekis A, Toonkel R, Karampitsakos T, Medapalli K, Ninou I, Aidinis V, Bouros D, Glassberg MK (2018) Mesenchymal stem cells for the treatment of idiopathic pulmonary fibrosis. Front Med (Lausanne) 5:142

121. Yang S, Liu P, Jiang Y, Wang Z, Dai H, Wang C (2021) Therapeutic applications of mesenchymal stem cells in idiopathic pulmonary fibrosis. Front Cell Dev Biol 9:639657

122. Han J, Li Y, Li Y (2019) Strategies to enhance mesenchymal stem cell-based therapies for acute respiratory distress syndrome. Stem Cells Int 2019:5432134

123. Qin H, Zhao A (2020) Mesenchymal stem cell therapy for acute respiratory distress syndrome: from basic to clinics. Protein Cell 11(10):707-722

124. Harrell CR, Jovicic BP, Djonov V, Volarevic V (2020) Therapeutic potential of mesenchymal stem cells and their secretome in the treatment of SARS-CoV-2-induced acute respiratory distress syndrome. Anal Cell Pathol (Amst) 2020:1939768

125. Gazdic M, Simovic Markovic B, Jovicic N, Misirkic-Marjanovic M, Djonov V, Jakovljevic V, Arsenijevic N, Lukic ML, Volarevic V (2017) Mesenchymal stem cells promote metastasis of lung cancer cells by downregulating systemic antitumor immune response. Stem Cells Int 2017:6294717

126. Jung PY, Ryu H, Rhee KJ, Hwang S, Lee CG, Gwon SY, Kim J, Kim J, Yoo BS, Baik SK et al (2019) Adipose tissue-derived mesenchymal stem cells cultured at high density express IFNbeta and TRAIL and suppress the growth of H460 human lung cancer cells. Cancer Lett 440-441:202-210

127. Cortes-Dericks L, Galetta D (2019) The therapeutic potential of mesenchymal stem cells in lung cancer: benefits, risks and challenges. Cell Oncol (Dordr) 42(6):727-738

128. Marinas-Pardo L, Mirones I, Amor-Carro O, Fraga-Iriso R, Lema-Costa B, Cubillo I, Rodriguez Milla MA, Garcia-Castro J, Ramos-Barbon D (2014) Mesenchymal stem cells regulate airway contractile tissue remodeling in murine experimental asthma. Allergy 69(6):730-740

129. Castro LL, Kitoko JZ, Xisto DG, Olsen PC, Guedes HLM, Morales MM, Lopes-Pacheco M, Cruz FF, Rocco PRM (2020) Multiple doses of adipose tissue-derived mesenchymal stromal cells induce immunosuppression in experimental asthma. Stem Cells Transl Med 9(2):250-260

130. Gu W, Song L, Li XM, Wang D, Guo XJ, Xu WG (2015) Mesenchymal stem cells alleviate airway inflammation and emphysema in COPD through down-regulation of cyclooxygenase-2 via p38 and ERK MAPK pathways. Sci Rep 5:8733

131. Cho JW, Park KS, Bae JY (2019) Effects of Wharton's jellyderived mesenchymal stem cells on chronic obstructive pulmonary disease. Regen Ther 11:207-211

132. Matthay MA, Calfee CS, Zhuo H, Thompson BT, Wilson JG, Levitt JE, Rogers AJ, Gotts JE, Wiener-Kronish JP, Bajwa EK et al (2019) Treatment with allogeneic mesenchymal stromal cells for moderate to severe acute respiratory distress syndrome (START study): a randomised phase 2a safety trial. Lancet Respir Med 7(2):154-162

133. Yen BL, Yen ML, Wang LT, Liu KJ, Sytwu HK (2020) Current status of mesenchymal stem cell therapy for immune/inflammatory lung disorders: Gleaning insights for possible use in COVID-19. Stem Cells Transl Med 9(10):1163-1173

134. Inamdar AC, Inamdar AA (2013) Mesenchymal stem cell therapy in lung disorders: pathogenesis of lung diseases and mechanism of action of mesenchymal stem cell. Exp Lung Res 39(8):315-327

135. Sadeghi S, Soudi S, Shafiee A, Hashemi SM (2020) Mesenchymal stem cell therapies for COVID-19: current status and mechanism of action. Life Sci 262:118493

136. Golchin A, Seyedjafari E, Ardeshirylajimi A (2020) Mesenchymal stem cell therapy for COVID-19: present or future. Stem Cell Rev Rep 16(3):427-433

137. Durand N, Mallea J, Zubair AC (2020) Insights into the use of mesenchymal stem cells in COVID-19 mediated acute respiratory failure. Npj Regen Med 5(1):17

138. Xiong J, Chen L, Zhang L, Bao L, Shi Y (2021) Mesenchymal stromal cell-based therapy: a promising approach for severe COVID-19. Cell Transplant 30:963689721995455

139. Almalki SG, Agrawal DK (2016) Key transcription factors in the differentiation of mesenchymal stem cells. Differentiation 92(1-2):41-51

140. Ma N, Gai H, Mei J, Ding FB, Bao CR, Nguyen DM, Zhong H (2011) Bone marrow mesenchymal stem cells can differentiate into type II alveolar epithelial cells in vitro. Cell Biol Int 35(12):1261-1266

141. Liu J, Peng D, You J, Zhou O, Qiu H, Hao C, Chen H, Fu Z, Zou L (2021) Type 2 alveolar epithelial cells differentiated from human umbilical cord mesenchymal stem cells alleviate mouse pulmonary fibrosis through beta-catenin-regulated cell apoptosis. Stem Cells Dev 30(13):660-670

142. Yadav P, Vats R, Bano A, Bhardwaj R (2020) Mesenchymal stem cell immunomodulation and regeneration therapeutics as an ameliorative approach for COVID-19 pandemics. Life Sci 263:118588

143. Shi Y, Wang Y, Li Q, Liu K, Hou J, Shao C, Wang Y (2018) Immunoregulatory mechanisms of mesenchymal stem and stromal cells in inflammatory diseases. Nat Rev Nephrol 14(8):493-507

144. Sette A, Crotty S (2021) Adaptive immunity to SARS-CoV-2 and COVID-19. Cell 184(4):861-880

145. Liu J, Li S, Liu J, Liang B, Wang X, Wang H, Li W, Tong Q, Yi J, Zhao L et al (2020) Longitudinal characteristics of lymphocyte responses and cytokine profiles in the peripheral blood of SARS-CoV-2 infected patients. EBioMedicine 55:102763

146. Liang X, Ding Y, Zhang Y, Tse HF, Lian Q (2014) Paracrine mechanisms of mesenchymal stem cell-based therapy: current status and perspectives. Cell Transplant 23(9):1045-1059

147. Chang C, Yan J, Yao Z, Zhang C, Li X, Mao HQ (2021) Effects of mesenchymal stem cell-derived paracrine signals and their delivery strategies. Adv Healthc Mater 10(7):e2001689

148. Cabler SS, French AR, Orvedahl A (2020) A cytokine circus with a viral ringleader: SARS-CoV-2-associated cytokine storm syndromes. Trends Mol Med 26(12):1078-1085

149. Mangalmurti N, Hunter CA (2020) Cytokine storms: understanding COVID-19. Immunity 53(1):19-25

150. Verma YK, Verma R, Tyagi N, Behl A, Kumar S, Gangenahalli GU (2021) COVID-19 and its therapeutics: special emphasis on mesenchymal stem cells based therapy. Stem Cell Rev Rep 17(1):113-131 
151. Obendorf J, Fabian C, Thome UH, Laube M (2020) Paracrine stimulation of perinatal lung functional and structural maturation by mesenchymal stem cells. Stem Cell Res Ther 11(1):525

152. Ellison-Hughes GM, Colley L, O'Brien KA, Roberts KA, Agbaedeng TA, Ross MD (2020) The Role of MSC therapy in attenuating the damaging effects of the cytokine storm induced by COVID-19 on the heart and cardiovascular system. Front Cardiovasc Med 7:602183

153. Xiang B, Chen L, Wang X, Zhao Y, Wang Y, Xiang C (2017) Transplantation of menstrual blood-derived mesenchymal stem cells promotes the repair of LPS-induced acute lung injury. Int J Mol Sci 18(4):689

154. Chen X, Wu Y, Wang Y, Chen L, Zheng W, Zhou S, Xu H, Li Y, Yuan L, Xiang C (2020) Human menstrual blood-derived stem cells mitigate bleomycin-induced pulmonary fibrosis through anti-apoptosis and anti-inflammatory effects. Stem Cell Res Ther 11(1):477

155. Karp JM, Leng Teo GS (2009) Mesenchymal stem cell homing: the devil is in the details. Cell Stem Cell 4(3):206-216

156. Liesveld JL, Sharma N, Aljitawi OS (2020) Stem cell homing: from physiology to therapeutics. Stem Cells 38(10):1241-1253

157. Nitzsche F, Muller C, Lukomska B, Jolkkonen J, Deten A, Boltze J (2017) Concise review: MSC adhesion cascadeinsights into homing and transendothelial migration. Stem Cells 35(6):1446-1460

158. Ullah M, Liu DD, Thakor AS (2019) Mesenchymal stromal cell homing: mechanisms and strategies for improvement. iScience $15: 421-438$

159. Lee KH, Tseng WC, Yang CY, Tarng DC (2019) The anti-inflammatory, anti-oxidative, and anti-apoptotic benefits of stem cells in acute ischemic kidney injury. Int J Mol Sci 20(14):3529

160. Zheng M, Gao Y, Wang G, Song G, Liu S, Sun D, Xu Y, Tian Z (2020) Functional exhaustion of antiviral lymphocytes in COVID-19 patients. Cell Mol Immunol 17(5):533-535

161. Murphy MB, Moncivais K, Caplan AI (2013) Mesenchymal stem cells: environmentally responsive therapeutics for regenerative medicine. Exp Mol Med 45:e54

162. Bernard O, Jeny F, Uzunhan Y, Dondi E, Terfous R, Label R, Sutton A, Larghero J, Vanneaux V, Nunes H et al (2018) Mesenchymal stem cells reduce hypoxia-induced apoptosis in alveolar epithelial cells by modulating HIF and ROS hypoxic signaling. Am J Physiol Lung Cell Mol Physiol 314(3):L360-L371

163. Khatri M, Richardson LA, Meulia T (2018) Mesenchymal stem cell-derived extracellular vesicles attenuate influenza virusinduced acute lung injury in a pig model. Stem Cell Res Ther 9(1): 17

164. Li F, Karlsson H (2017) Antiviral effect of IDO in mouse fibroblast cells during influenza virus infection. Viral Immunol 30(7):542-544

165. Tripathi S, Tecle T, Verma A, Crouch E, White M, Hartshorn KL (2013) The human cathelicidin LL-37 inhibits influenza A viruses through a mechanism distinct from that of surfactant protein D or defensins. J Gen Virol 94(Pt 1):40-49

166. Metcalfe SM (2020) Mesenchymal stem cells and management of COVID-19 pneumonia. Med Drug Discov 5:100019

167. Hur YH, Cerione RA, Antonyak MA (2020) Extracellular vesicles and their roles in stem cell biology. Stem Cells 38(4):469-476

168. van Niel G, D’Angelo G, Raposo G (2018) Shedding light on the cell biology of extracellular vesicles. Nat Rev Mol Cell Biol 19(4):213-228

169. O'Brien K, Breyne K, Ughetto S, Laurent LC, Breakefield XO (2020) RNA delivery by extracellular vesicles in mammalian cells and its applications. Nat Rev Mol Cell Biol 21(10):585-606

170. Koniusz S, Andrzejewska A, Muraca M, Srivastava AK, Janowski M, Lukomska B (2016) Extracellular vesicles in physiology, pathology, and therapy of the immune and central nervous system, with focus on extracellular vesicles derived from mesenchymal stem cells as therapeutic tools. Front Cell Neurosci 10:109

171. Abraham A, Krasnodembskaya A (2020) Mesenchymal stem cell-derived extracellular vesicles for the treatment of acute respiratory distress syndrome. Stem Cells Transl Med 9(1):28-38

172. Guo H, Su Y, Deng F (2021) Effects of mesenchymal stromal cell-derived extracellular vesicles in lung diseases: current status and future perspectives. Stem Cell Rev Rep 17(2):440-458

173. Dauletova M, Hafsan H, Mahhengam N, Zekiy AO, Ahmadi M, Siahmansouri H (2021) Mesenchymal stem cell alongside exosomes as a novel cell-based therapy for COVID-19: a review study. Clin Immunol 226:108712

174. Morrison TJ, Jackson MV, Cunningham EK, Kissenpfennig A, McAuley DF, O'Kane CM, Krasnodembskaya AD (2017) Mesenchymal stromal cells modulate macrophages in clinically relevant lung injury models by extracellular vesicle mitochondrial transfer. Am J Respir Crit Care Med 196(10):1275-1286

175. Monsel A, Zhu YG, Gennai S, Hao Q, Hu S, Rouby JJ, Rosenzwajg M, Matthay MA, Lee JW (2015) Therapeutic effects of human mesenchymal stem cell-derived microvesicles in severe pneumonia in mice. Am J Respir Crit Care Med 192(3):324-336

176. Li JW, Wei L, Han Z, Chen Z (2019) Mesenchymal stromal cellsderived exosomes alleviate ischemia/reperfusion injury in mouse lung by transporting anti-apoptotic miR-21-5p. Eur J Pharmacol 852:68-76

177. Basiri A, Mansouri F, Azari A, Ranjbarvan P, Zarein F, Heidari A, Golchin A (2021) Stem cell therapy potency in personalizing severe COVID-19 treatment. Stem Cell Rev Rep 17(1):193-213

178. Musial C, Gorska-Ponikowska M (2021) Medical progress: stem cells as a new therapeutic strategy for COVID-19. Stem Cell Res 52:102239

179. Sahu KK, Siddiqui AD, Cerny J (2021) Mesenchymal stem cells in COVID-19: a journey from bench to bedside. Lab Med 52(1):24-35

180. Leng Z, Zhu R, Hou W, Feng Y, Yang Y, Han Q, Shan G, Meng F, Du D, Wang S et al (2020) Transplantation of ACE2(-) mesenchymal stem cells improves the outcome of patients with COVID-19 pneumonia. Aging Dis 11(2):216-228

181. Xu X, Jiang W, Chen L, Xu Z, Zhang Q, Zhu M, Ye P, Li H, Yu L, Zhou X et al (2021) Evaluation of the safety and efficacy of using human menstrual blood-derived mesenchymal stromal cells in treating severe and critically ill COVID-19 patients: an exploratory clinical trial. Clin Transl Med 11(2):e297

182. Meng F, Xu R, Wang S, Xu Z, Zhang C, Li Y, Yang T, Shi L, Fu J, Jiang $T$ et al (2020) Human umbilical cord-derived mesenchymal stem cell therapy in patients with COVID-19: a phase 1 clinical trial. Signal Transduct Target Ther 5(1):172

183. Shi L, Huang H, Lu X, Yan X, Jiang X, Xu R, Wang S, Zhang C, Yuan X, Xu Z et al (2021) Effect of human umbilical cordderived mesenchymal stem cells on lung damage in severe COVID-19 patients: a randomized, double-blind, placebo-controlled phase 2 trial. Signal Transduct Target Ther 6(1):58

184. Lanzoni G, Linetsky E, Correa D, Messinger Cayetano S, Alvarez RA, Kouroupis D, Alvarez Gil A, Poggioli R, Ruiz P, Marttos AC et al (2021) Umbilical cord mesenchymal stem cells for COVID-19 acute respiratory distress syndrome: a double-blind, phase 1/2a, randomized controlled trial. Stem Cells Transl Med 10(5):660-673

185. Shu L, Niu C, Li R, Huang T, Wang Y, Huang M, Ji N, Zheng Y, Chen X, Shi L et al (2020) Treatment of severe COVID-19 with human umbilical cord mesenchymal stem cells. Stem Cell Res Ther 11(1):361

186. Sánchez-Guijo F, García-Arranz M, López-Parra M, Monedero P, Mata-Martínez C, Santos A, Sagredo V, Álvarez-Avello J-M, Guerrero JE, Pérez-Calvo C et al (2020) Adipose-derived 
mesenchymal stromal cells for the treatment of patients with severe SARS-CoV-2 pneumonia requiring mechanical ventilation. A proof of concept study. EClinicalMedicine 25:100454

187. Feng Y, Huang J, Wu J, Xu Y, Chen B, Jiang L, Xiang H, Peng Z, Wang X (2020) Safety and feasibility of umbilical cord mesenchymal stem cells in patients with COVID-19 pneumonia: a pilot study. Cell Prolif 53(12):e12947

188. Hashemian SR, Aliannejad R, Zarrabi M, Soleimani M, Vosough M, Hosseini SE, Hossieni H, Keshel SH, Naderpour Z, Hajizadeh-Saffar E et al (2021) Mesenchymal stem cells derived from perinatal tissues for treatment of critically ill COVID-19-induced ARDS patients: a case series. Stem Cell Res Ther 12(1):91

189. Zengin R, Beyaz O, Koc ES, Akinci IO, Kocagoz S, Sagcan G, Ovali E, Cuhadaroglu C (2020) Mesenchymal stem cell treatment in a critically ill COVID-19 patient: a case report. Stem Cell Investig 7:17

190. Liang B, Chen J, Li T, Wu H, Yang W, Li Y, Li J, Yu C, Nie F, $\mathrm{Ma} Z$ et al (2020) Clinical remission of a critically ill COVID-19 patient treated by human umbilical cord mesenchymal stem cells: a case report. Medicine (Baltimore) 99(31):e21429

191. Zhang Y, Ding J, Ren S, Wang W, Yang Y, Li S, Meng M, Wu T, Liu D, Tian S et al (2020) Intravenous infusion of human umbilical cord Wharton's jelly-derived mesenchymal stem cells as a potential treatment for patients with COVID-19 pneumonia. Stem Cell Res Ther 11(1):207

192. Tang L, Jiang Y, Zhu M, Chen L, Zhou X, Zhou C, Ye P, Chen $\mathrm{X}$, Wang B, Xu Z et al (2020) Clinical study using mesenchymal stem cells for the treatment of patients with severe COVID-19. Front Med 14(5):664-673

193. Levy O, Kuai R, Siren EMJ, Bhere D, Milton Y, Nissar N, De Biasio M, Heinelt M, Reeve B, Abdi R et al (2020) Shattering barriers toward clinically meaningful MSC therapies. Sci Adv 6(30):eaba6884

194. Connors JM, Levy JH (2020) COVID-19 and its implications for thrombosis and anticoagulation. Blood 135(23):2033-2040

195. Nahum J, Morichau-Beauchant T, Daviaud F, Echegut P, Fichet J, Maillet JM, Thierry S (2020) Venous thrombosis among critically ill patients with coronavirus disease 2019 (COVID-19). JAMA Netw Open 3(5):e2010478

196. Bonaventura A, Vecchie A, Dagna L, Martinod K, Dixon DL, Van Tassell BW, Dentali F, Montecucco F, Massberg S, Levi M et al (2021) Endothelial dysfunction and immunothrombosis as key pathogenic mechanisms in COVID-19. Nat Rev Immunol 21(5):319-329

197. Loo J, Spittle DA, Newnham M (2021) COVID-19, immunothrombosis and venous thromboembolism: biological mechanisms. Thorax 76:412-420

198. Piazza G, Morrow DA (2020) Diagnosis, management, and pathophysiology of arterial and venous thrombosis in COVID19. JAMA 324(24):2548-2549

199. Moll G, Ankrum JA, Kamhieh-Milz J, Bieback K, Ringden O, Volk HD, Geissler S, Reinke P (2019) Intravascular mesenchymal stromal/stem cell therapy product diversification: time for new clinical guidelines. Trends Mol Med 25(2):149-163

200. Moll G, Geissler S, Catar R, Ignatowicz L, Hoogduijn MJ, Strunk D, Bieback K, Ringden O (2016) Cryopreserved or fresh mesenchymal stromal cells: only a matter of taste or key to unleash the full clinical potential of MSC therapy? Adv Exp Med Biol 951:77-98

201. Moll G, Alm JJ, Davies LC, von Bahr L, Heldring N, StenbeckFunke L, Hamad OA, Hinsch R, Ignatowicz L, Locke M et al (2014) Do cryopreserved mesenchymal stromal cells display impaired immunomodulatory and therapeutic properties? Stem Cells 32(9):2430-2442

202. Glassberg MK, Minkiewicz J, Toonkel RL, Simonet ES, Rubio GA, DiFede D, Shafazand S, Khan A, Pujol MV, LaRussa VF et al (2017) Allogeneic human mesenchymal stem cells in patients with idiopathic pulmonary fibrosis via intravenous delivery (AETHER): a phase I safety clinical trial. Chest 151(5):971-981

203. Chambers DC, Enever D, Ilic N, Sparks L, Whitelaw K, Ayres J, Yerkovich ST, Khalil D, Atkinson KM, Hopkins PM (2014) A phase 1b study of placenta-derived mesenchymal stromal cells in patients with idiopathic pulmonary fibrosis. Respirology 19(7):1013-1018

204. Zheng G, Huang L, Tong H, Shu Q, Hu Y, Ge M, Deng K, Zhang L, Zou B, Cheng B et al (2014) Treatment of acute respiratory distress syndrome with allogeneic adipose-derived mesenchymal stem cells: a randomized, placebo-controlled pilot study. Respir Res 15:39

205. Choudhery MS, Harris DT (2020) Stem cell therapy for COVID-19: possibilities and challenges. Cell Biol Int $44: 2182-2191$

206. Golchin A (2021) Cell-based therapy for severe COVID-19 patients: clinical trials and cost-utility. Stem Cell Rev Rep 17(1):56-62

207. Dominici M, Le Blanc K, Mueller I, Slaper-Cortenbach I, Marini F, Krause D, Deans R, Keating A, Prockop D, Horwitz E (2006) Minimal criteria for defining multipotent mesenchymal stromal cells. The International Society for Cellular Therapy position statement. Cytotherapy 8(4):315-317

208. Peng H, Gong T, Huang X, Sun X, Luo H, Wang W, Luo J, Luo B, Chen Y, Wang X et al (2020) A synergistic role of convalescent plasma and mesenchymal stem cells in the treatment of severely ill COVID-19 patients: a clinical case report. Stem Cell Res Ther 11(1):291

209. Costa LA, Eiro N, Fraile M, Gonzalez LO, Saa J, Garcia-Portabella P, Vega B, Schneider J, Vizoso FJ (2021) Functional heterogeneity of mesenchymal stem cells from natural niches to culture conditions: implications for further clinical uses. Cell Mol Life Sci 78(2):447-467

210. Markov A, Thangavelu L, Aravindhan S, Zekiy AO, Jarahian M, Chartrand MS, Pathak Y, Marofi F, Shamlou S, Hassanzadeh A (2021) Mesenchymal stem/stromal cells as a valuable source for the treatment of immune-mediated disorders. Stem Cell Res Ther 12(1):192

211. Tufan AC (2021) Mesenchymal stem cells as a treatment strategy for coronavirus disease 2019 (COVID-19): need for authority regulations and clinical guidelines. Curr Stem Cell Res Ther 16(4):465-480

212. Zhao Q, Han Z, Wang J, Han Z (2021) Development and investigational new drug application of mesenchymal stem/stromal cells products in China. Stem Cells Transl Med 10(Suppl 2):S18-S30

213. Xu R, Shi L, Xie W-F, Xu Z, Meng F-P, Fu J-L, Yuan X, Huang L, Shi M, Li Y et al (2021) Diagnosis and treatment guidelines for mesenchymal stem cell therapy for coronavirus disease 2019 (Beijing, 2021). Infect Dis Immun 1(2):68-73

214. Zumla A, Wang FS, Ippolito G, Petrosillo N, Agrati C, Azhar EI, Chang C, El-Kafrawy SA, Osman M, Zitvogel L et al (2020) Reducing mortality and morbidity in patients with severe COVID-19 disease by advancing ongoing trials of mesenchymal stromal (stem) cell (MSC) therapy - achieving global consensus and visibility for cellular host-directed therapies. Int J Infect Dis 96:431-439

215. Tiwari R, Dhama K, Sharun K, Iqbal Yatoo M, Malik YS, Singh R, Michalak I, Sah R, Bonilla-Aldana DK, Rodriguez-Morales AJ (2020) COVID-19: animals, veterinary and zoonotic links. Vet Q 40(1):169-182

216. Pinky L, Gupta S, Krishnakumar V, Sharma Y, Dinda AK, Mohanty S (2021) Mesenchymal stem cell derived exosomes: a nano platform for therapeutics and drug delivery in combating COVID-19. Stem Cell Rev Rep 17(1):33-43 
217. Rezakhani L, Kelishadrokhi AF, Soleimanizadeh A, Rahmati S (2021) Mesenchymal stem cell (MSC)-derived exosomes as a cell-free therapy for patients Infected with COVID-19: real opportunities and range of promises. Chem Phys Lipids 234:105009

218. Sengupta V, Sengupta S, Lazo A, Woods P, Nolan A, Bremer N (2020) Exosomes derived from bone marrow mesenchymal stem cells as treatment for severe COVID-19. Stem Cells Dev 29(12):747-754

219. Kassem DH, Kamal MM (2020) Mesenchymal stem cells and their extracellular vesicles: a potential game changer for the COVID-19 crisis. Front Cell Dev Biol 8:587866
220. Akbari A, Rezaie J (2020) Potential therapeutic application of mesenchymal stem cell-derived exosomes in SARS-CoV-2 pneumonia. Stem Cell Res Ther 11(1):356

Publisher's Note Springer Nature remains neutral with regard to jurisdictional claims in published maps and institutional affiliations. 